NISTIR 8244

\title{
2018 National Institute of Standards and Technology Environmental Scan
}

\author{
Jason Boehm \\ Heather Evans \\ Ajit Jillavenkatesa \\ Maria Nadal \\ Mark Przybocki \\ Paul Witherell \\ Rebecca Zangmeister
}

This publication is available free of charge from:

https://doi.org/10.6028/NIST.IR.8244 
NISTIR 8244

\title{
2018 National Institute of Standards and Technology Environmental Scan
}

\author{
Jason Boehm \\ Heather Evans \\ Ajit Jillavenkatesa \\ Maria Nadal \\ Mark Przybocki \\ Paul Witherell \\ Rebecca Zangmeister \\ Program Coordination Office \\ Office of the NIST Director
}

This publication is available free of charge from:

https://doi.org/10.6028/NIST.IR.8244

March 2019

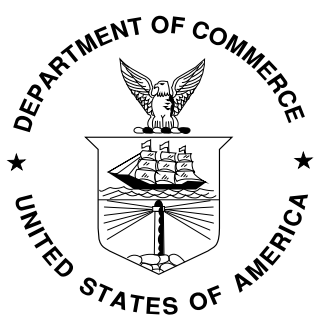

U.S. Department of Commerce

Wilbur L. Ross, Jr., Secretary

National Institute of Standards and Technology Walter Copan, NIST Director and Undersecretary of Commerce for Standards and Technology 


\title{
Preface
}

This environmental scan and analyses provide a snapshot of external opportunities and threats originating from societal, geopolitical, policy and technological developments as of June 2018. This document was developed by the NIST Program Coordination Office (PCO) to provide context for NIST senior leadership as they developed a new strategic plan for NIST during FY 18 and FY 19. The analyses are in no way intended to be a comprehensive list of all the opportunities and threats to NIST, but instead attempt to highlight some significant trends and developments that may impact NIST. Any viewpoints and recommendations are made strictly based on observations and are not an official NIST position. In developing this scan, the PCO staff used a variety of external sources, which are cited in the bibliography and footnotes.

\begin{abstract}
The 2018 National Institute of Standards and Technology Environmental Scan provided an analysis of key external factors that could impact NIST and the fulfillment of its mission as the agency creates strategic plans for coming years. The analyses were conducted through four separate lenses: Societal, Political, Geopolitical, and Technological. Observations highlighted cover the range from the political climate NIST currently faces to challenges to NIST's leadership in metrology to the new opportunities provided by new breakthrough technology innovations. Analyzing the view through these four lenses provides a holistic view of the environment NIST faces moving forward.
\end{abstract}

\section{Key words}

Environmental Scan, NIST Policy, Strategic Planning 2018 


\section{Table of Contents}

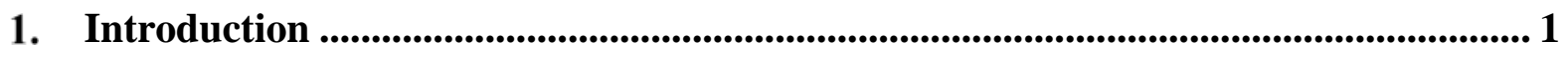

2. Societal Landscape ............................................................................................................. 1

2.1. Societal Changes ......................................................................................... 1

2.1.1. Aging Population and Generational Divides ......................................................... 1

2.1.2. Immigration Trends ................................................................................... 2

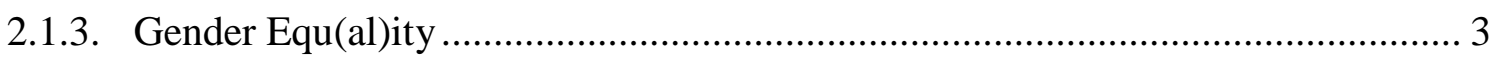

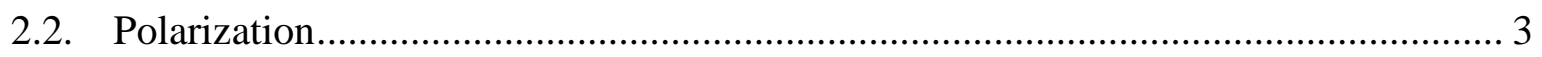

2.2.1. Income Disparity ……………................................................................. 3

2.2.2. Urban-Suburban-Rural Divide ................................................................... 4

2.2.3. Information Divide .................................................................................. 4

2.2.4. Tech-lash ............................................................................................... 4

2.2.5. Distrust .............................................................................................. 5

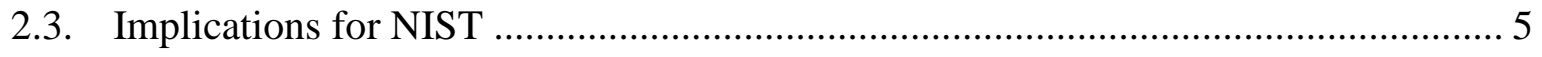

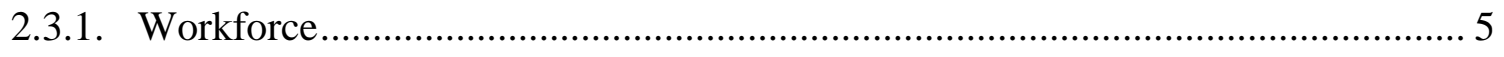

2.3.2. Distrust and Skepticism.............................................................................. 7

3. Investment and Geopolitical Landscape........................................................................ 8

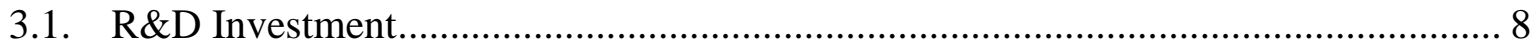

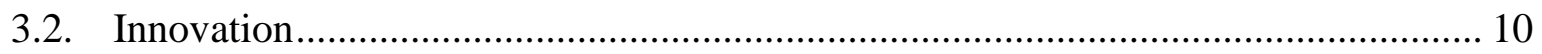

3.3. Student and Workforce Development, Attraction and Retention.............................. 11

3.4. Metrology and Standards............................................................................... 13

3.5. Implications for NIST …………................................................................. 14

3.5.1. Declining Level of Investment ..................................................................... 14

3.5.2. Workforce and Collaborations ....................................................................... 14

3.5.3. Status as an NMI and Standardization Expert.................................................... 14

4. Political and Policy Landscape ....................................................................................... 15

4.1. Congressional and Executive Branch Dynamics...................................................... 15

4.2. Implications for NIST ………….................................................................. 16

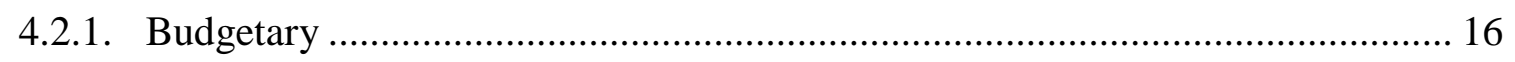

4.2.2. Programmatic Impacts and the Future of NIST ............................................... 17

5. Technology and Science Landscape.................................................................................. 19

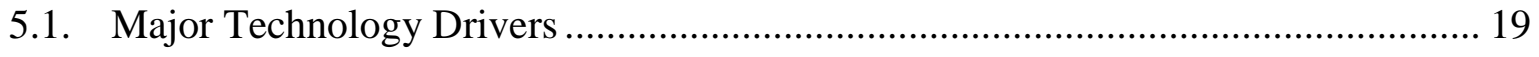

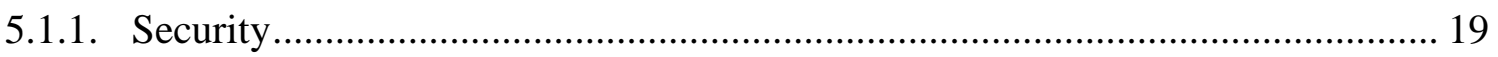

5.1.2. Sustainable Energy Innovations ....................................................................... 19 


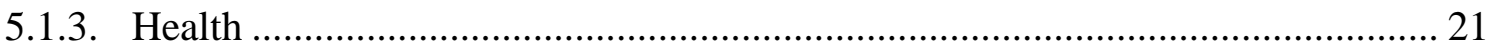

5.1.4. Smart Cities and Communities ................................................................... 22

5.1.5. Drones and Autonomous Vehicles ........................................................... 23

5.1.6. Human Augmentation ................................................................................. 24

5.1.7. $5 \mathrm{G}$ and Next-Generation Communication...................................................... 25

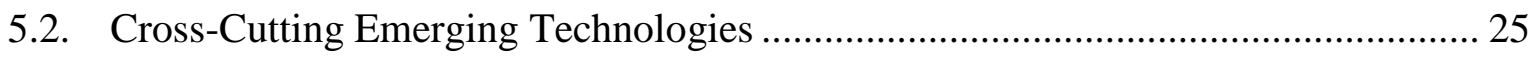

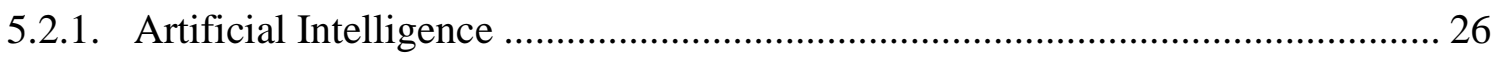

5.2.2. Quantum Information Science and Technology .......................................... 27

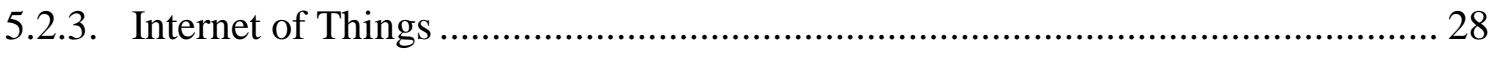

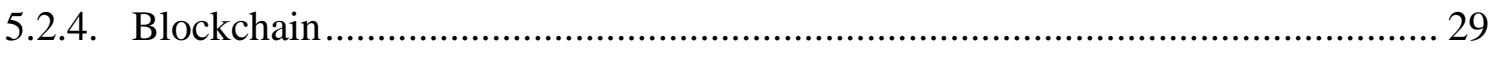

6. Conclusion ................................................................................................................. 31

7. Bibliography ............................................................................................................................ 32

\section{List of Figures}

Fig. 1a. Gross domestic expenditures on R\&D by select countries from 1981 to 2015. Data are for the top eight R\&D-performing countries and the EU [37]. Note PPP refers to Purchasing Power Parity.

Fig. 2. U.S. Federal R\&D funding as percent of GDP (Note that beginning in FY 2017, a new official definition of R\&D was adopted by federal agencies. Late-stage development, testing and evaluation programs, primarily within the Department of Defense, are no longer counted as R\&D). Chart derived from data from [40]. 10

Fig. 3. Recipients of first university natural sciences and engineering degrees [37]........... 12 Fig. 4. Number of ISO Technical Committees Participation by Country; data captured from ISO members database on 6/12/2018: https://www.iso.org/members.html. 13 


\section{Introduction}

Since its inception as the National Bureau of Standards (1901), the National Institute of Standards and Technology (NIST) has played a defining role in standardization and innovation in the U.S. Situated within the Department of Commerce, NIST's mission is “To promote U.S. innovation and industrial competitiveness by advancing measurement science, standards, and technology in ways that enhance economic security and improve our quality of life.” This mission is achieved through NIST's core competencies of measurement science, rigorous traceability, and development and use of standards, as well as core organization values of perseverance, integrity, inclusivity, and excellence. As NIST maintains consistency with its core competencies and organizational values, it is imperative that NIST be organizationally and programmatically nimble so that its programs can respond to changing technologies and societal needs. In 2018, as NIST plans for the near- and midterm future, decisions must be made about where efforts should be placed to most effectively execute the NIST mission.

Environmental scans provide a mechanism for gathering prospective information during strategic planning exercises. They can provide insights into current external factors that may influence how an institution plans and operates. In an attempt to provide a holistic view of the current environment, this exercise was conducted through four separate lenses: Societal, Political, Geopolitical, and Technological.

The following sections address the views through each of these lenses and provide an informative breakdown of ongoing trends in the current global environment. These trends may not directly influence NIST's strategic direction but will likely impact mission-oriented decisions of the future, including decisions on workforce, processes, and partners in the long term.

\section{Societal Landscape}

The societal landscape scan focuses on two major trends: societal changes and increased polarization. The subtopics addressed in this societal landscape scan include: the aging population of the U.S., immigration, gender equality, the urban-suburban-rural divide, the information divide, and distrust which is sometimes manifest through backlash against new technologies. Thoughts on the implications for NIST regarding these topics are framed by issues observed in the workforce and distrust and skepticism subtopics.

\subsection{Societal Changes}

\subsubsection{Aging Population and Generational Divides}

By 2030, the U.S. Census Bureau projects that one in every five U.S. residents will be older than age 65 (including the entire baby boomer generation), and this population subset will outnumber children for the first time in U.S. history [1]. As the population ages, the proportion of retired adults increases: in 2020 there will be 3.5 working-age adults for every retirement-age person, declining to 2.5 working-age adults for every retirement-age person in 2060 [1]. This projection presents a major challenge for federal programs such as Social Security and Medicare, but also suggests that working adults may have increased caregiving 
responsibilities for the elderly as life expectancies continue to increase due to modern medicine and healthcare.

In 2017, the lifetime cost of care for a person living with dementia borne directly by families through out-of-pocket costs and the value of unpaid care is estimated to be almost a quarter of a million dollars [2]. There are an estimated 5.5 million Americans age 65 and older living with Alzheimer's-associated dementia in 2018. The number of people 65 and older with Alzheimer's dementia is projected to reach 7.1 million by 2025, an increase of $29 \%$ from 2018. New findings from a March 2018 “Alzheimer's Facts and Figures” report show that for the second consecutive year, total payments for individuals living with Alzheimer's or other dementias are projected to surpass a quarter of a trillion dollars ( $\$ 277$ billion), a $\$ 20$ billion increase over 2017. [2] By 2050, the total cost of care for Alzheimer's is projected to increase to more than $\$ 1.1$ trillion and will have a significant effect on the U.S. economy.

As a result of the aging workforce, for the first time in U.S. history there are now five generations included in the U.S. workforce. In 2017, the workforce was composed of $2 \%$ Silent/Greatest Generation (b. <1945), 25\% Baby Boomer Generation (b. 1946 to 1964), 33\% Generation X (b. 1965 to 1980), 35\% Millennial Generation (b. 1981 to 1996) and 5\% PostMillennial Generation (b. $\geq 1997$ ) [3]. The differences in life experiences and context of these populations can lead to workplace conflict about choosing where and when to work (e.g., telecommuting, flexible work schedules) and how to communicate (e.g., face-to-face meetings, phone calls, voice messages, emails, texting or instant messaging) [4].

\subsubsection{Immigration Trends}

Immigration influences nearly every policy area of concern, from jobs and the economy to education, health care and federal, state and local government budgets [5]. More than 40 million people living in the U.S. in 2015 were born in other countries and almost an equal number have at least one foreign-born parent. Together these groups comprise almost one in four Americans [5]. The number of immigrants in the U.S. continues to increase. According to the U.S. Census Bureau projections, the 2030s are to be a transformative decade for the U.S. in that net international migration is projected to overtake native birthrate in 2030 as the primary driver of population growth in the United States. Overall, the U.S. population is projected to grow at a slower pace, age considerably and become more racially and ethnically diverse.

The skills of the immigrant population and how their education and experience levels compare to those of the native-born residents are key determinants of the impact their arrival will have on the wages and employment of those already living in the U.S. [5]. Unskilled or insufficiently skilled individuals are disproportionately represented in new arrivals. However, a significant number of immigrants are highly skilled and have advanced educational degrees. There has been a recent influx of highly skilled workers under the H-1B visa program and increasing numbers of international students, both undergraduate and graduate, enrolling in U.S. universities [5]. This influx reflects, at least in part, the high demand for highly skilled labor in STEM fields (science, technology, engineering and mathematics) by American firms in the high-tech sector and in research laboratories in universities and the private sector. 
A Brookings Institute analysis of the U.S. Census 2015 American Community Survey shows that recent immigrants are more highly educated than those of the past and "college graduates are more prevalent among recent immigrant adults than among all adults in 90 of the 100 largest metropolitan areas" [6]. This report also states that immigration is especially economically important for areas that are experiencing a decline in net domestic migration and that U.S. immigration levels are currently fueling most community population gains; gains are especially important as the nation's population gets older and fertility remains low.

Public perception of immigration may also be shifting. According to a June 2017 Gallup poll, U.S. adults are more likely to say that immigrants improve life in the U.S. than when surveyed in 2007 [7]. According to the poll, most Americans now say immigrants have a positive effect on food, music and the arts (57\%), while nearly half say immigration benefits the economy in general (45\%); both measures are up 17 percentage points from 2007. Americans' views that immigrants have a positive effect on social and moral values (31\%) and taxes (23\%) are both up by 12 percentage points. Smaller but statistically significant increases were seen among those who say immigrants positively affect job opportunities (20\%) and the crime situation (9\%).

\subsubsection{Gender Equ(al)ity}

The \#MeToo movement spotlighting sexual misconduct has led to examination and more open discussions of related issues regarding gender equ(al)ity in the workplace. Gender equality (the condition in which workers rights, responsibilities and opportunities will not depend on their gender) is the end and gender equity (fairness of treatment for all according to their respective needs) is the means to that end. Some statistics that point to the existence of gender inequality include roughly $42 \%$ of employed women say they have experienced some form of gender discrimination at work [8]; roughly 50\% of women in STEM fields will leave their STEM careers, $30 \%$ of whom cite workplace climate as the main reason [9]; and for every dollar earned by a man in STEM, a woman in STEM earns 84 cents [10]. Gender imbalance in workforce attrition, promotions and pay differences are central areas for action.

\subsection{Polarization}

Today's society can be characterized by increased polarization and differences of opinion. This polarization, and an overall sense of divisiveness, has been perceived to have become stronger in recent years and may be influenced by the factors discussed below.

\subsubsection{Income Disparity}

The financial crisis of 2008 was a major setback for economies around the world, but most countries' total wealth has rebounded and surpassed pre-crisis levels [11]. However, unequal sharing of the economic pie has caused rising social discontent [12]. As of 2016, data from the Survey of Consumer Finances shows that U.S. upper-income families have median wealth greater than that prior to the Great Recession, whereas middle- and lower-income families have not yet recovered their wealth from 2007 levels; their wealth is equivalent to levels recorded in 1989 [13]. The Great Recession, which nearly halved the wealth of lowerand middle-income families, has driven wealth inequality to record levels since the Federal Reserve began collecting this type of data in 1983. 


\subsubsection{Urban-Suburban-Rural Divide}

The United States is growing in population, becoming more racially and ethnically diverse, and aging, but these trends are occurring at different rates in urban, suburban and rural communities [14]. The percentage of the population that is non-white is much larger in urban areas (56\%) than in suburban (32\%) or rural (21\%) areas; the overall population since 2000 has increased more in suburban (+16\%) and urban (+13\%) areas than in rural $(+3 \%)$ areas; and the percent change in population of those aged 65 and older since 2000 has increased more in suburban (+39\%) areas than in urban (+26\%) or rural $(+22 \%)$ areas.

The perspectives and political landscapes of these communities are shifting in correspondence with the demographic changes. Overall, the percentage of residents that think most people do not understand the problems they face is larger in the rural (70\%) and urban (65\%) communities than in suburban (52\%) areas. The largest splits between community sentiments come from misgivings about demographic changes and perceived biases in federal assistance, according to a Washington Post-Kaiser Family Foundation survey of nearly 1,700 Americans [15]. "Alongside a strong rural social identity, the survey shows that disagreements between rural and urban America ultimately center on fairness: Who wins and who loses in the new American economy, who deserves the most help in society and whether the federal government shows preferential treatment to certain types of people” [15].

\subsubsection{Information Divide}

The differences in community perspectives are heightened by the digital age of information exchange that allows for facts and opposing 'counter facts' to look identical, making some individuals vulnerable to accepting and acting on misinformation. A 2016 study of 920 news outlets and 376 million Facebook users found that the news sphere of Facebook is clustered and dominated by a community structure, and users tend to focus their attention on a single group of news outlets [16]. The intermingling of information dissemination and social platforms in the digital age has resulted in disparate communities of people who not only have differing viewpoints, but do not agree on a single set of information or facts on which those viewpoints are based.

Furthermore, this information/misinformation can be deliberately spread by malicious actors. A study of the internet activity prior to the UK Brexit vote showed that in the 48 hours around the referendum, Russian-linked accounts posted more than 45,000 tweets encouraging people to vote for Brexit; it has also been shown that for every bot tweet that resulted in a retweet, on average seven re-tweets came from humans [17]. Separating truth from fiction will only become more difficult with the use of voice- and video-morphing technology [18]. "If trust in what politicians say is already low, it could soon be non-existent," writes reporter Rachel Botsman, "artificial intelligence and augmented reality, for example, will mean that we'll have to question everything we see, hear or read forensically, to decide if it's the real deal or clever fakery” [19].

\subsubsection{Tech-lash}

Society is continuously connected to an influx of information while simultaneously generating and exposing new types of personal data. Smartphone owners interact with their phones an average of 85 times a day, including immediately upon waking up, just before going to sleep and even in the middle of the night [20]. This state of continuous connection 
is new: only $4 \%$ of U.S. adults owned smartphones in 2007; today, $77 \%$ of U.S. adults (92\% of those between 18 and 35 years old) own smartphones [20]. The National Highway Traffic Safety Administration attributed 3,450 deaths in 2016 to distracted driving [21]. A 2017 study showed a correlation between the presence of a smartphone with reduced available cognitive capacity, and cognitive costs are highest for those with the most smartphone dependence [20]. Another 2017 study, published in the American Journal of Preventive Medicine, concluded that of the 1,787 U.S. 19- to 32-year-olds surveyed, those who spent the most time on social media (more than 2 hours per day) had twice the rate of perceived social isolation than those who spent 30 minutes or less per day on social media sites [22].

Some of the largest companies (e.g., Facebook, Google, Twitter) of the digital age are under further scrutiny as information regarding the use and capitalization of personal data, fake news, hate speech and the sponsorship of political ads on social media have come to light. The now-defunct Cambridge Analytica's use of data from at least 50 million Facebook users without their permission, and in violation of the laws of some countries, has raised important questions about data governance and consumer privacy [23]. The General Data Protection Regulation (GDPR) that protects the privacy of European citizens by giving users control over their personal data went into effect in the European Union on May 25, 2018, with similar measures being considered in the U.S. The U.S. Congress is contemplating legislation that would require more transparency regarding sponsorship of online political ads.

As the use of personal information becomes public knowledge, citizens are intuitively challenging the 'move fast and break things' Silicon Valley mindset and business model while pointing fingers at where it is failing to earn the trust of society [24]. One theory is that at the heart of tech-lash is a movement towards a future that will benefit the planet and the human experience; but, to reach this future, institutions must listen to and respond to technology backlash in a way that results in the development of technologies that will benefit society and that society can trust. [24].

\subsubsection{Distrust}

One can surmise, based on the prior subtopics, that widespread distrust in the U.S. is on the rise. According to the 2018 Edelman Trust Barometer, the trust index (TI) [25]. in the U.S. decreased between 2017 and 2018, falling a combined total of -37 points across four generalized institutions: non-government organizations, businesses, government and media [25]. This general feeling of distrust extends to science. Subsets of the population that do not accept climate change, evolution or the use of vaccines arrive at their opinions based on their information sources and the "tribes" they belong to. "A lot of [distrust in science] has to do with tribalism - you believe what the people in your group believe, because membership in that group is more important to you than the truth" [26]. Some have suggested that if scientific findings are applied as ways to fix societal problems, they might be more readily accepted [26].

\subsection{Implications for NIST}

\subsubsection{Workforce}

\subsubsection{Aging Population}

As the population ages and stratifies, the differences between the five generations identified in Section 2.1.1 will be exaggerated in the workplace. Generational-based conflict in teams 
usually stems from differing expectations around when and where to work (e.g., teleworking or flexible schedules), modes of communication (e.g., face-to-face meetings, voicemail, email, instant messaging), scheduling (e.g., use of calendaring software) and obtaining new skills (e.g., taking a formal course or learning on the fly) [27]. Workplace bias against others for reasons such as working different hours, using an 'impersonal' style of communication, failing to keep their calendar up to date or using an online video to learn how to complete a work task can inhibit the collaborative team environment that NIST thrives upon. Forthright and open discussions about workplace expectations, without implicating ageism, can be used to bring attention to preferences caused by generational gaps. Differences in generational workstyles may affect how well new technology and software tools for administrative tasks (e.g., new software for recording time and attendance, booking travel, and tracking property) is accepted by NIST staff.

As the population ages, NIST staff may also find themselves in the role of caregivers in their private lives. The continued support of flexible work schedules and support groups for caregivers will be needed. Lastly, even though the population is aging, it is not accurate for NIST to assume that the retirement rates will trend with the rates of individuals entering typical retirement age. The general trend projected by the U.S. Census Bureau is that older people are currently working and will continue to work for an increasing number of years and earn more annually [28]. This may have significant implications for staff advancement, gender equality and the ability to recruit and retain skilled talent at NIST.

\subsubsection{Immigration}

The immigration of highly skilled and educated individuals to the U.S. is an asset for NIST. NIST's guest researcher population consists of more than $50 \%$ foreign individuals ${ }^{1}$. Highly skilled STEM immigrants have been sought by some as a source of talent to strengthen the U.S. STEM workforce. Of note is that there have been differing reports as to whether there is a STEM talent pool crisis or surplus. A May 2015 Bureau of Labor Statistics report revealed that there is both a STEM crisis and surplus depending on where you look [29]. The report concludes that for the government and government-related job sector, certain STEM disciplines have a shortage of positions at the Ph.D. level (e.g., materials science engineering, nuclear engineering) and in general (e.g., systems engineers, cybersecurity, and intelligence professionals) due to the U.S. citizenship requirement. In contrast, an oversupply of biomedical engineers exists at the Ph.D. level. STEM talent pool shortages and citizenship requirements of NIST staff positions may hinder NIST's ability to hire qualified scientists and researchers, particularly for technological fields with shortages of skilled talent.

\subsubsection{Equity In Career Advancement}

NIST has not been immune to the need for examination and more open discussions of issues related to gender equity in the workplace. Inclusivity is one of NIST's core values, yet women and minorities are underrepresented in the NIST scientific workforce, especially in senior ranks. NIST recently established the Steering Group for Equity in Career Advancement in Laboratory Programs to explore and address the underrepresentation of

1 The number of NIST Associates designates as Foreign Guest Researchers (492) and Domestic Guest Researchers (863) were collected from NIST MML organization tables on June 12, 2018. 
women and minorities at NIST. Although the effort currently focuses on NIST Laboratory Programs, the intention is to expand it to explore and address the inequities that affect the entire NIST workforce.

\subsubsection{Distrust and Skepticism}

NIST has a reputation of being a trusted organization within the scientific community. In the current climate of distrust and skepticism, especially mistrust of science, there are fewer and fewer institutions that remain avowedly objective and unbiased. NIST, an organization that prides itself on its objectivity and lack of scientific bias [30], is in a sense the federal "trust" agency. NIST has an enormous opportunity to promote the mechanisms by which good measurements lead to conclusive and trustworthy science, and vice versa.

The general climate of distrust and skepticism [31], compounded by the information divide, could have far-reaching, harmful effects on the collegial and collaborative spirit of NIST employees. One way to combat distrust may be to reinforce the culture of trust within NIST leadership and as an organization. Adam Bryant, the author of the "Corner Office" column for The New York Times revealed that the most important trait of successful executives is that of trustworthiness. He explains that a reputation for trustworthiness can be built by taking specific actions to back up beliefs, and to demonstrate to employees how to do the same [32]. Bryant suggests that organizational leaders should be aware that their employees are evaluating trustworthiness through their observations and experiences of their actions: "Do we trust them to do the right thing? Will they be straight with us and not shave corners off truth? Do they own their mistakes; give credit where credit is due; care about their employees as people as opposed to assets? Do they manage down as well as up? [33]” It is important for NIST leadership to be especially cognizant of the optics of their actions, as any poor communication or lack of transparency from senior leadership may stoke distrust amongst the NIST community and affect external perceptions. 


\section{Investment and Geopolitical Landscape}

The current geopolitical landscape is as competitive as ever. Industrialized and emerging economies alike have become steadily more R\&D intensive [34]. Many of today's emerging technologies (e.g., quantum computing and artificial intelligence) have been described as "the next Space Race," initiating large investments and intense competitiveness amongst nations. Investment and Geopolitical Landscape explores various factors that may affect NIST's standing on the world stage, particularly U.S. investment in metrology as it compares to similar investments by governments around the world and the impact of these investments.

\subsection{R\&D Investment}

The U.S. has long been recognized as a global science and technology (S\&T) leader, spending more on research and development $(\mathrm{R} \& \mathrm{D})$ than any other country and accounting for around 40\% of total OECD (Organization for Economic Co-operation and Development) countries’ R\&D expenditures in 2016 [35]. Relatively unchanged funding levels have led the Nation's international position to be challenged perhaps now more than ever: while the U.S. maintains a strong position in overall gross R\&D investment (\$496.6 B in 2015), other nations, especially China ( $\$ 408.8 \mathrm{~B}$ in 2015), are quickly closing the gap in total R\&D expenditures (Figure 1a), and have long been in front in R\&D Intensity (Figure 1b, Amount of R\&D as percentage of Gross GDP). In 2017, China’s President Xi Jinping announced plans to make China the world's biggest superpower by 2050, fueled in part by large investment in R\&D. China (not an OECD member) has continued its steady increase in R\&D intensity, reaching $2.12 \%$ in 2015, and is on course to match the overall OECD R\&D intensity by 2020 [36]. China's spending on R\&D grew by an average of $18 \%$ per year between 2010 and 2015, a number that is four times faster than U.S. spending growth and will likely surpass U.S. R\&D spending within the next 5 years [37].

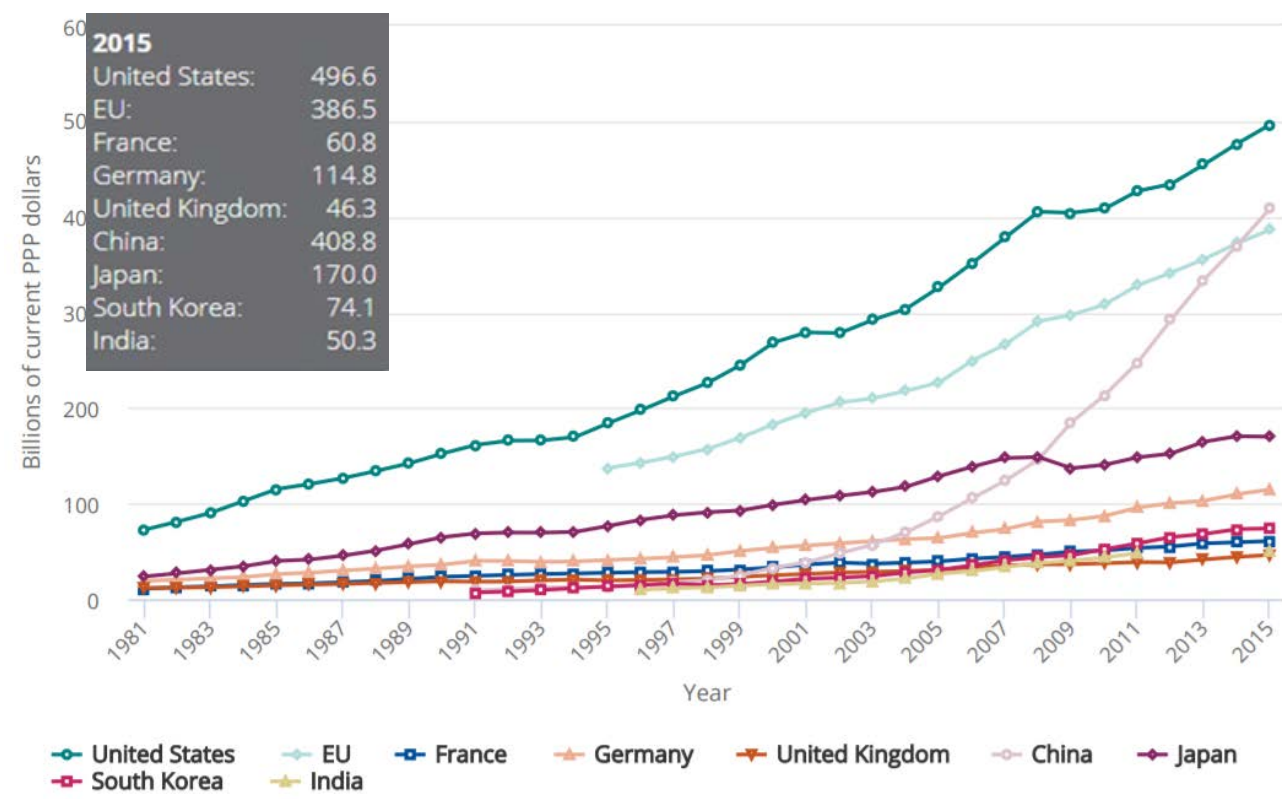

Fig. 1a. Gross domestic expenditures on R\&D by select countries from 1981 to 2015. Data are for the top eight R\&D-performing countries and the EU [37]. Note PPP refers to Purchasing Power Parity. 


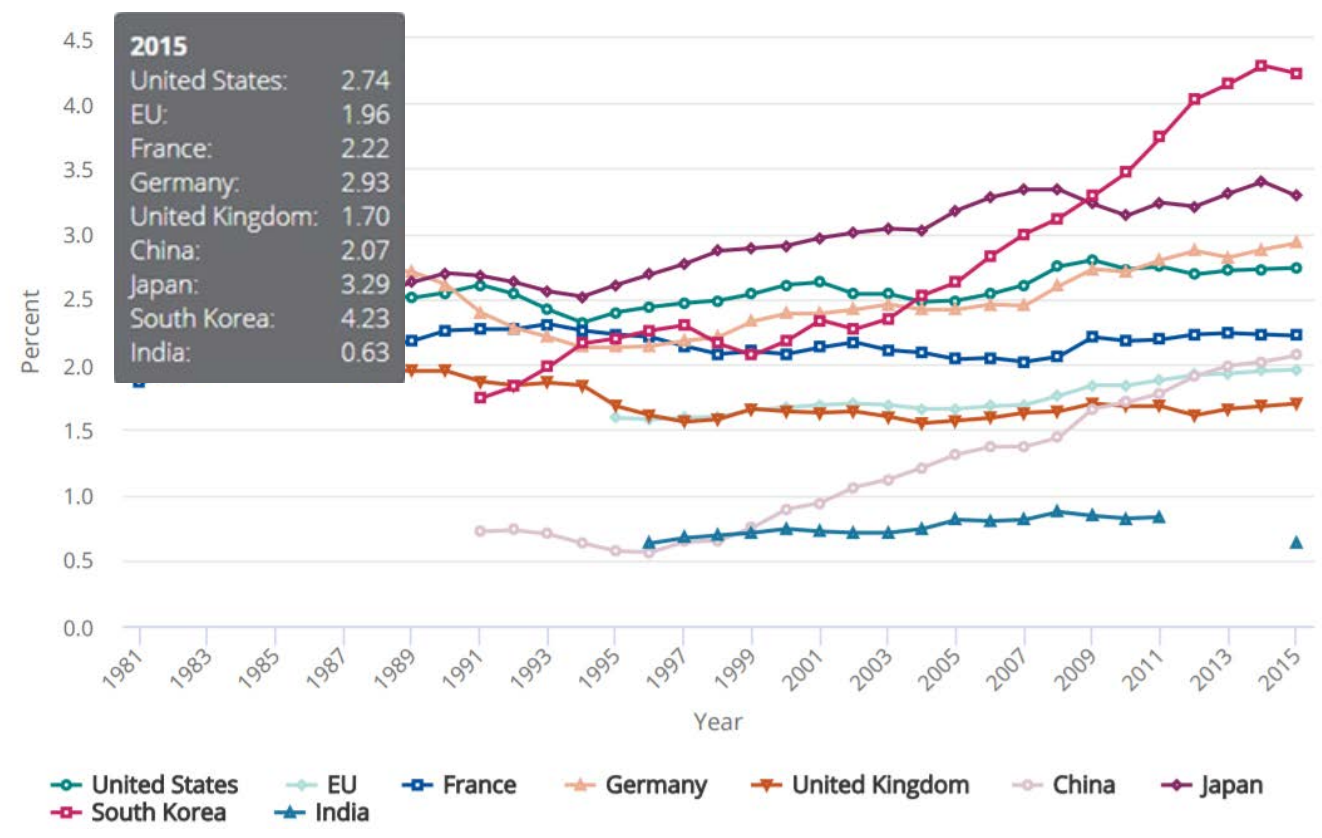

Fig. 1b. Gross domestic expenditures on R\&D as a share of gross domestic product by country from 1981 to 2015. Data are for the top eight R\&D-performing countries and the EU [37]. Data are not available for all countries for all years.

While the United States' gross R\&D investment, which considers both public and private investments, has grown, federal R\&D investment has continued to shrink over the years, reaching a record low of 23\% of gross R\&D in 2015 [38]. For comparison, Germany's (28\%) and the United Kingdom's (28\%) shares were somewhat higher while China's was slightly below, at 21\%. In the U.S., the total federal R\&D investment (including research, development and facilities) has continued to shrink over the past several decades (Figure 2), to the point where it currently stands at approximately $0.7 \%$ of GDP, a number that has been argued should be closer to $2 \%$ for a strong economy [39]. Of the total U.S. federal R\&D investment, the R\&D performed by the government accounted for about $11 \%$ of the national total in 2015. The share of R\&D performed by governments ranged from $7 \%$ to $53 \%$ across the other countries [37]. For comparison, South Korea (12\%), China (16\%), Germany (14\%) and France (13\%) showed shares similar to the U.S. 


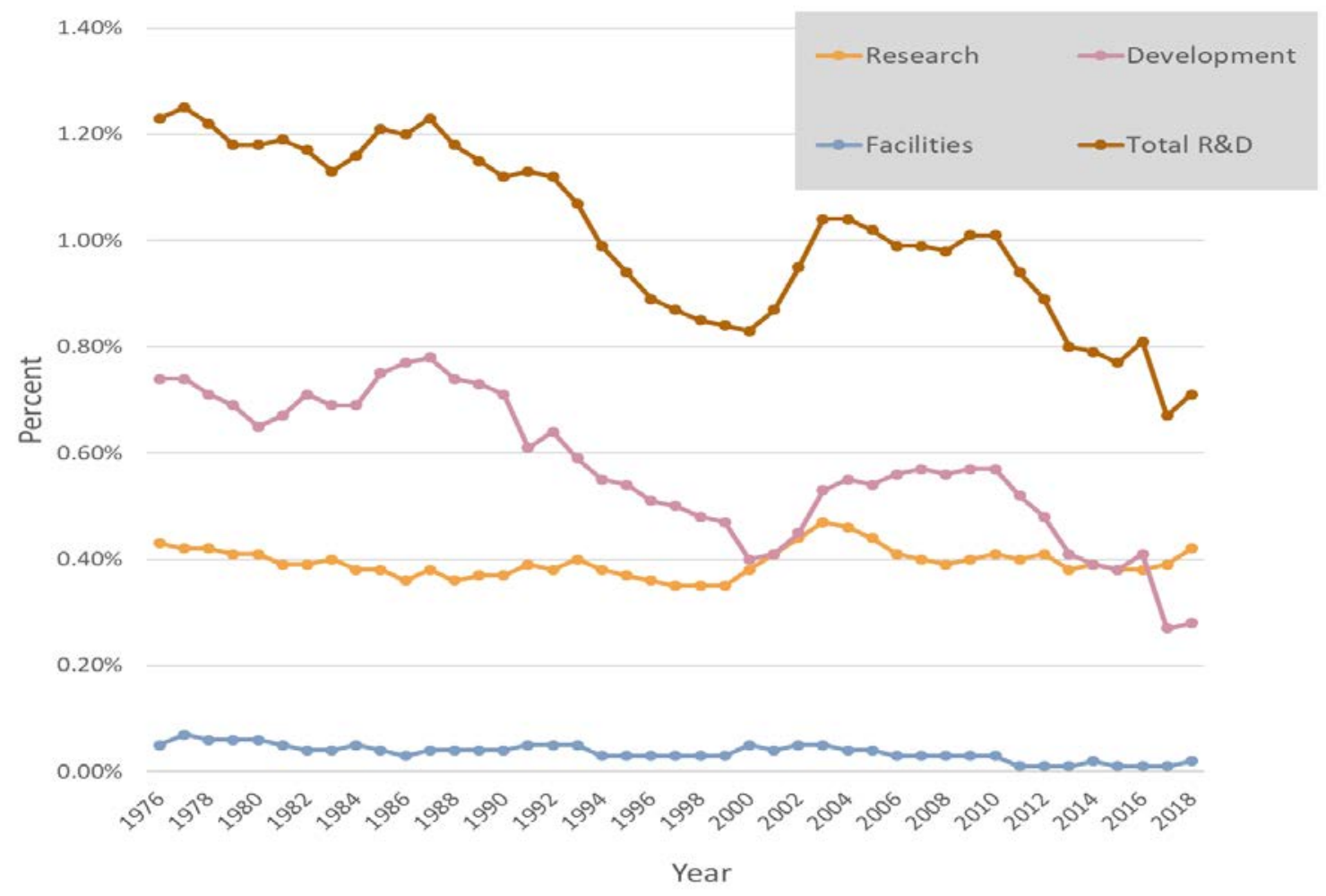

Fig. 2. U.S. Federal R\&D funding as percent of GDP (Note that beginning in FY 2017, a new official definition of R\&D was adopted by federal agencies. Late-stage development, testing and evaluation programs, primarily within the Department of Defense, are no longer counted as $R \& D)$. Chart derived from data from [40].

\subsection{Innovation}

The U.S. innovation ecosystem is being challenged and handicapped by the strategic use of industrial and S\&T policies from other countries, especially China. China's very aggressive industrial policy focuses on growing Chinese companies by multiple means, including subsidies for Chinese industry, forced technology transfer and use of anti-monopoly laws that further impact the traditional U.S. role as the leading technology innovator [41] [42]. The potential consequences of shifting foreign-driven innovation are significant, especially in emerging fields such as advanced communication technologies, quantum science, artificial intelligence (AI) and bioengineering. As scientific fields mature, leading innovators are able to seize the opportunity to set strategies around technology deployment and applications while also benefiting from technological superiority. Indicators of U.S. innovation have been slowly falling in recent years as other countries have expanded the range and scope of their R\&D activities. As one example, Chinese domestic patent applications have exploded, rising from almost nothing at the beginning of the century to 928,000 applications in 2014, 40\% more than the U.S. $(579,000)$ and almost three times more than Japan $(326,000)$ (Note: while this is just a measure of patent filings in China with the Chinese Patent Office, these numbers do not provide any insights into the quality of patents, the types of patents, etc.). In one innovation index, the U.S. recently fell to 11th place from 9th in a drop largely driven by declining educational statistics [43]. 
Foreign governments are becoming increasingly effective in defining policies around emerging technologies and the associated research. For instance, many refer to today's advanced manufacturing initiatives as "Industry 4.0," a phrase coined by the German government's Industrie 4.0 initiative. The implication is that many of the U.S. research efforts associated with advanced manufacturing are at risk of being either knowingly or unknowingly influenced by German interests [44]. As other countries focus their investments and efforts around specific technologies, the U.S. is at risk of losing not only leadership but also influence. For example, China is dramatically increasing its investment in quantum science with plans for a $\$ 10$ billion quantum science research center [45], combined with investments from Chinese companies like Alibaba, which is reportedly spending \$15 billion on quantum computing and AI research [46]. Faced with large state investments in disruptive (uproots an established technology) emerging technologies such as quantum, AI, robotics and bioengineering, losing influence could be catastrophic to not only the economy but also to national security [47].

Implications of lost R\&D leadership are also spilling into the industrial sector. For instance, China is the number one sales market for industrial robots (the U.S. is $4^{\text {th }}$ ) and is projected to be the benefactor of $40 \%$ of the total worldwide sales for robots by 2019 [48].

\subsection{Student and Workforce Development, Attraction and Retention}

The U.S. is facing critical challenges to its S\&T workforce in terms of both the number and the quality of S\&T students. In the international arena, the U.S. performs in the middle of the pack among developed countries on the Trends in International Mathematics and Science Study (TIMSS) assessments and at the bottom on the Program for International Student Assessment (PISA). These rankings indicate that the in-house development of the U.S. S\&T workforce is sub-optimal in K-12 programs [37]. When focusing on secondary education and advanced degrees, the U.S. has lost ground in the development of S\&T graduates obtaining their first university degrees (Figure 3). In 2007, China surpassed the U.S. as the world's largest awarder of natural sciences and engineering doctoral degrees (though the numbers of doctoral degrees in these fields in these two countries remain close) [37]. The high growth of graduate education in China has been the result of large government investments in higher education over the last 20 years (Note; while considering these trends, it is also important to consider the educational quality and skills of these educational programs $)$. 


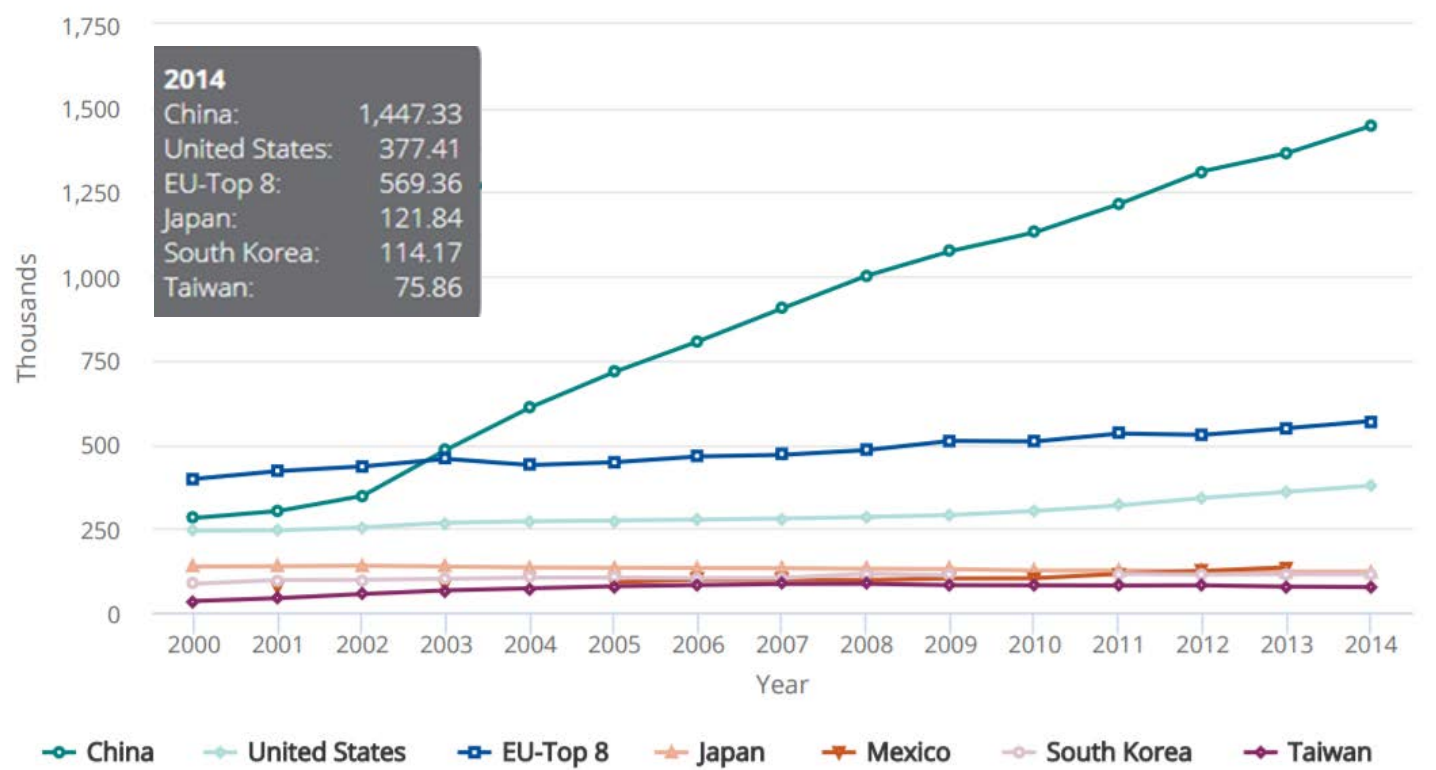

Fig. 3. Recipients of first university natural sciences and engineering degrees [37].

Foreign students and researchers are important pillars of U.S. STEM activities [49]. Historically, more internationally mobile students (undergraduate and graduate) choose to attend educational institutions in the U.S. than any other country. However, the percentage of internationally mobile students hosted in the U.S. has declined in recent years, from $25 \%$ in 2000 to 19\% in 2016 [36]. Other top destinations include the United Kingdom (10\%), Australia (6\%), France (5\%), Russia (5\%) and Germany (5\%). The U.S. proportion is likely to decrease further if the declining trend in international enrollment continues. International (and U.S.) researchers are increasingly willing to relocate to countries with developing R\&D capabilities such as Singapore, Korea, United Arab Emirates and Oman where they are finding better compensation and more sustained support to conduct their research [50]. Attracting top R\&D talent to the U.S. has become progressively complicated due to policy changes impacting fields of research open to foreign nationals [51]. These policies are beginning to limit U.S. access to large pools of foreign researchers, resulting in redistribution of S\&T talent and subsequently R\&D output and impact around the world.

One decisive indicator of this ongoing shift of S\&T talent and the respective output is the number of science and engineering (S\&E) publications. U.S. S\&E publication production grew from 383,000 in 2006 to almost 410,000 in 2016, an increase of only 7\%. In this same time period, the publication output from the world as a whole increased by $46 \%$. As the U.S. publication volume is leveling off, other economies' publication volumes are growing more rapidly [37]. The U.S. global share fell from 24.4\% in 2006 to 17.8\% in 2016. The top five countries producing S\&E publications in 2016 are China (18.6\% of global output volume), the U.S. (17.8\%), and India (4.8\%). When treated as one entity, the European Union (EU) accounted for $26.7 \%$ of the world's S\&E publications in 2016 [37]. 


\subsection{Metrology and Standards}

NIST's standing as a leading national metrology institute (NMI) has long given NIST its core identity. As other nations increase their R\&D funding, new investments are being made in NMIs around the world. As a result, NIST's standing and influence as a lead metrology institute is not assured. While NIST continues to maintain its considerable number of Calibration and Measurement Capabilities (CMCs), other nations are increasing the number of CMCs they provide [52]. With CMCs providing the technical basis for wider agreements negotiated for international trade, commerce and regulatory affairs, a proportional decrease in CMCs will cause the U.S. to lose leverage while other countries strengthen their influence in various international trade arenas. The implications of this trend are greater when seeking to establish a presence in an emerging technology.

While the U.S. maintains its strong presence in the international standards arenas such as the International Organization for Standardization (ISO) and the International Electrotechnical Commission (IEC), other nations are increasing their participation and leadership roles. For example, China and India rank among the world leaders in ISO technical committee participation, as seen in Figure 4. Increased participation makes these countries well positioned to influence international technical standards. This influence may include the introduction of domestically-developed technologies as the basis for these international standards.

Number of ISO Technical Committees (TCs) Participating in by Country
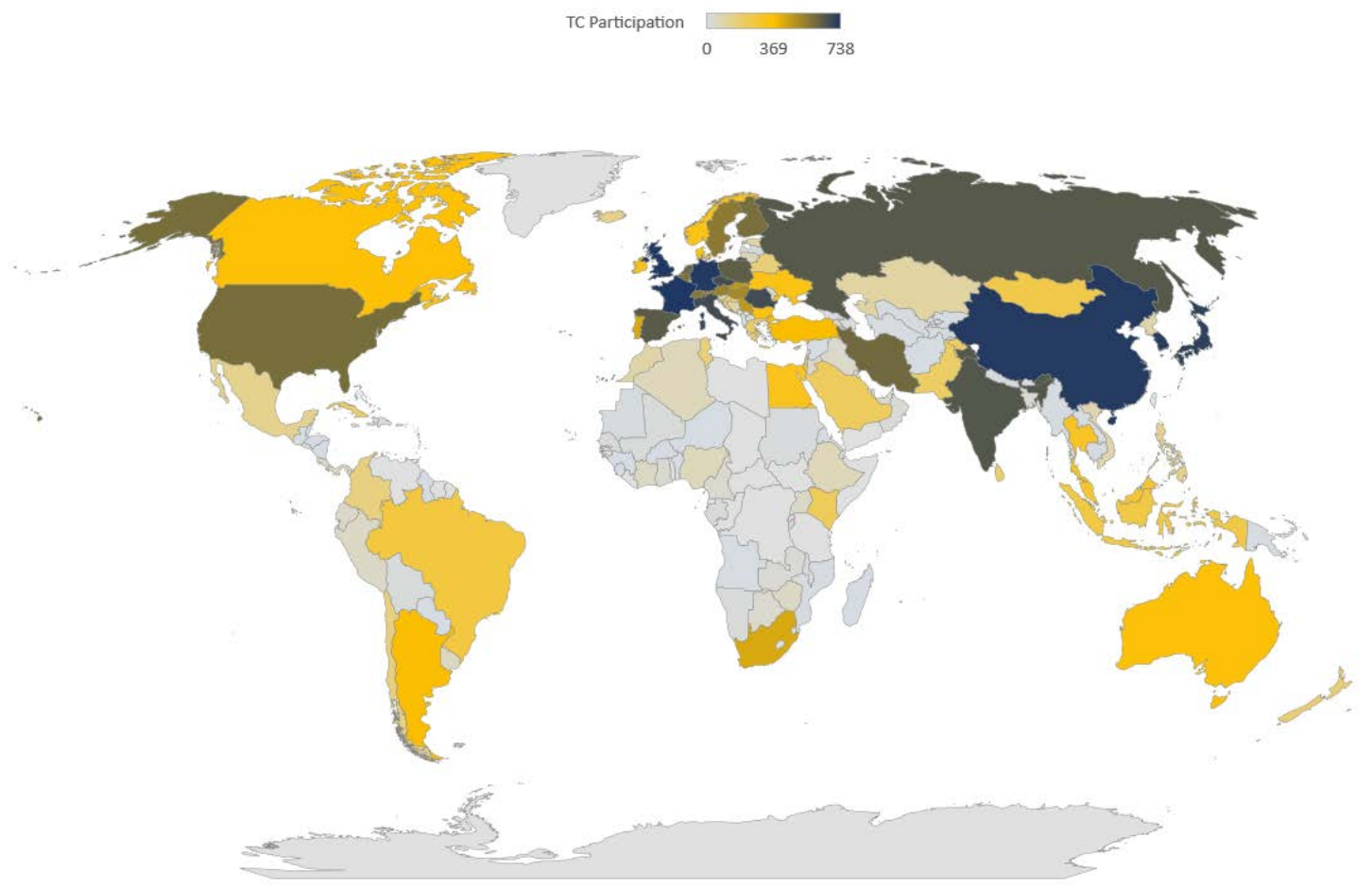

Fig. 4. Number of ISO Technical Committees Participation by Country; data captured from ISO members database on 6/12/2018: https://www.iso.org/members.html. 


\subsection{Implications for NIST}

\subsubsection{Declining Level of Investment}

Decreasing levels of Federal R\&D funding are likely to impact resources available to NIST, particularly when compared to funding for other science agencies such as the National Science Foundation (NSF), the National Institutes of Health (NIH), the U.S. Department of Energy (DOE), Department of Defense (DOD). Potentially faced with declining levels of investment, NIST may be required to make tough decisions regarding the reallocation of funds to meet emerging priorities, including those at the direction of the Administration and Congress. Reallocating funds to meet emerging priorities can lead to the weakening of existing areas of strength, such as NIST's core metrology functions. Furthermore, funding pressures could force NIST to adopt practices to maximize the flexibility of its research portfolio at the expense of continuity. This approach could adversely impact NIST's ability to maintain long-term core competencies in metrology.

\subsubsection{Workforce and Collaborations}

NIST has long benefited from an open research environment where some of the brightest minds around the globe come to collaborate with NIST researchers. Guest researchers (including NIST contractors) have had an enormous influence on the quality, thoroughness and impact of NIST-led research. NIST's guest researchers often provide immediate and flexible expertise, particularly in fields where expertise is hard to find among US citizens, to help in delivering the NIST mission. If access to this pool of researchers is restricted, NIST's ability to deliver on its mission through world-leading collaborations will be severely impacted.

\subsubsection{Status as an NMI and Standardization Expert}

While the U.S. has maintained its efforts, other countries continue to increase their investments in their NMI standards and CMCs. As noted above, CMCs can provide a technical basis for international trade, commerce and regulatory affairs. Involvement in new CMC activities without additional funding will put existing CMC activities at risk, forcing prioritization and decisions around which efforts are more important. In addition, NIST is threatened with possible diminished stature on the international stage due to diluted resources. Similar risks exist in the consensus standard arena, where increases in standards developing organization (SDO) activities compound the challenges created by increasing participation from non-traditional participants. Subsequently, NIST may need to become more selective in where it contributes its expertise in consensus standards development activities. 


\section{Political and Policy Landscape}

NIST's budget and programmatic priorities are strongly influenced by Congress and the executive branch. The current landscape and the dynamics between Congress and the executive branch leadership poses several political and policy-related developments and implications for NIST.

\subsection{Congressional and Executive Branch Dynamics}

There are stark and deeply entrenched differences in opinion between the two parties and the two chambers that impact many issues of significance to NIST. The narrow margins in the Senate and philosophical differences between the different factions in both parties in the House are challenging bipartisan support on many issues, such as: the regulation of technology, support for fundamental R\&D, the role of government in science and technology, and the size of the federal government budget. Political views continue to polarize much of the U.S., including: the extent of investments in R\&D, support for manufacturing-focused initiatives, the extent and nature of U.S. engagement in multi-lateral organizations such as the World Trade Organization, and the U.S. approach to global trade (multilateral vs. bilateral).

Despite these dynamics, it is evident that there is strong brand recognition of NIST in Congress, and the roles NIST plays. While many Congressional members and staff are not aware of the specifics of NIST work, scope of activities or mission, they routinely hear from constituents about specific activities such as the NIST Cybersecurity Framework or the Manufacturing Extension Partnership. Furthermore, constituents often recommend NIST as an organization to address their specific challenges without consideration of whether NIST has the expertise, the budget, or the mandate to work in that specific area. In many instances, NIST has become a victim of its own success. NIST's reputation for technical excellence, rigor and lack of bias often lead Congressional leaders and staff to task NIST with responsibilities that may not fit within its mission or in areas where NIST does not have relevant expertise or available resources.

Most Congressional leaders do not have a comprehensive understanding of the nuanced role NIST plays in supporting the development of voluntary consensus standards, or the standards development ecosystem writ large. Recent requests from Congressional leaders for NIST to take on roles, such as auditing federal agencies' cybersecurity approaches, highlight this challenge. In contrast, when Congressional staff work closely with NIST leaders and provide NIST staff the opportunity to share perspectives on issues of mutual interest, the resulting process can be very productive for all. For instance, Congressional staffers recently engaged with NIST staff to develop the National Quantum Initiative Act, Public Law No: 115-368, supporting quantum science R\&D and technology development while leveraging NIST's strengths in a clearly defined role and in a manner consistent with NIST capabilities and priorities.

Some senior positions in key White House offices such as in the White House Office of Science and Technology Policy (OSTP) and the National Security Council (NSC), as well as key political offices in Departments and Agencies, have remained vacant, or were filled with acting appointments at the time of writing. These positions have traditionally played a critical 
role in translating Administration objectives into actionable priorities for federal agencies, including NIST, and are critical for coordination between federal agencies and with the private sector.

NIST is still viewed as the go-to agency for many emerging technologies and other challenging issues. The strong relationship established between the NIST Director and senior White House officials in various Executive Office of the President (EOP) offices has helped position NIST in a leadership role in priority areas such as artificial intelligence and quantum engineering. NIST has had several detailees serve in the White House Office of Science and Technoloyg Policy (OSTP), including in the roles of Principal Assistant Director, Physical Sciences and Engineering, Director of the National Coordination Office for the National Information Technology Research and Development Program, and Assistant Director for Quantum Information Science. Similarly, strong engagement and outreach by the NIST Director to the technology policy leadership in the National Economic Council (NEC) has raised awareness about the importance of standards, NIST's role in standards, nextgeneration wireless communication technologies (5G), cybersecurity and the digital economy from an economic security perspective. This approach has helped establish multiple channels for NIST to convey the importance of NIST work, particularly a research, measurements and standards focus for economic security and competitiveness for the nation.

\subsection{Implications for NIST}

Current political developments create significant implications for NIST that impact its ability to develop and implement programs in an organized manner. The implications are not just budgetary, but also affect NIST's ability to identify and develop new programs that can help U.S. industry stay competitive among the increasing high-tech competition from other countries.

\subsubsection{Budgetary}

The President's proposed budgets have sent a strong message that the Administration's priorities are focused on non-discretionary spending for defense and national security. The Administration's proposed budgets for FY 18 and FY 19 requested significant cuts to the NIST scientific and technical programs. In addition, these budgets did not support continuing the Hollings Manufacturing Extension Partnership (MEP) program and proposed significant reductions to NIST's other extramural programs. In contrast, Congress has taken a different approach, where, after a relatively flat appropriated budget for FY 17, the appropriated budget for FY 18 saw increases to all NIST’s budget line items. Most noteworthy was the strong budgetary support for NIST's infrastructure. Increases to the NIST Safety, Capacity, Maintenance and Major Repairs (SCMMR) budget provided much needed financial resources to replace failing infrastructure (including Building 245 on the Gaithersburg campus) and execute long overdue repairs. This funding represented a dramatic shift among Senate appropriations staff to commit resources for infrastructure maintenance and upgrades. The difference between the 2018 President's budget request (\$725 M for NIST) and the appropriated budget (\$1.2 B) exemplifies the significant challenges that budgetary uncertainties pose for NIST. While the relatively flat FY 17 budget and the increase in the FY 18 budget represent positive developments, these are likely outliers rather than the norm. 
Additional budgetary impacts include the challenging planning processes associated with Congressional delays in passing a budget and the associated continuing resolution spending authorizations. The result of these challenges is that NIST staff are significantly limited in being able to make definitive, long-term spending plans. Budgetary guidance from the Administration, particularly when planning for significant reductions, requires managers to identify programs to reduce or eliminate. Such deliberations, even if not acted upon in final congressional appropriations, have adverse impacts on staff morale and productivity. Volatile funding conditions create challenges in staff recruitment, jeopardizing NIST's ability to ensure a healthy and vibrant talent pool. In programs such as the MEP, which the Administration has indicated its desire to eliminate, NIST has significant challenges in retaining well-connected expert staff. Consequently, when appropriations come through, NIST is faced with the challenge of having the money but not the staff who can effectively implement program requirements.

While it may be tempting to think of this as a passing phase, this funding environment has existed for some time and is likely to continue. Over the past few years, Congress has mostly been unable to pass budgets on time (before October 1) [53]. Budget challenges are exacerbated in several ways, including: the bipartisan nature of Congress that is increasingly viewed as dysfunctional [54]; the significant difference of opinion between Congress and the Administration on funding priorities; and the vocal voices in both Congress and the Administration articulating for strong reductions in federal spending to reduce the budget deficit.

\subsubsection{Programmatic Impacts and the Future of NIST}

While there is strong support for specific NIST programs among some Congressional members and staff, there is a limited understanding of NIST's role and how NIST operates. This notion is evidenced by instances such as H.R. 1224- NIST Cybersecurity Framework, Assessment, and Auditing Act of $2017^{2}$, where Congressional leaders sought to assign NIST a quasi-enforcement role relating to cybersecurity. Seemingly, the lack of progress by industry on specific issues or the inability of other agencies to deliver has increasingly prompted Congress or the Administration to consider assigning NIST new roles.

Current Congressional or Administration actions could have strong programmatic impacts. Issues such as remote identifications of drones, the development of a privacy framework and standards for space traffic management are all areas where NIST has limited or narrowly focused expertise, and thus is ill-suited to lead efforts. If tasked to tackle such issues as unfunded mandates, NIST's limited resources would quickly be taxed and strong concerns may arise about NIST's ability to deliver a quality product on time. The impact of unfunded mandates can be widespread, as they require NIST to draw resources away from other programs.

Raising awareness about NIST's programs and expertise requires considerable time and effort to ensure that Administration leaders, Congressional members and staff understand what NIST can do and deliver. A strategic approach to raising NIST awareness may include

\footnotetext{
${ }^{2}$ https://www.congress.gov/bill/115th-congress/house-bill/1224
} 
representation in key Administration offices such as the Office of the U.S. Trade Representative (USTR), OSTP, NSC, NEC, DOC Secretary's offices or Congressional committees. Creating opportunities for developmental or detail assignments for NIST staff would benefit both the organization and the individual. A NIST employee with strong technical foundations, an interest in policy and good communication skills can gain valuable experience while providing significant value to NIST within these offices. Incentives may help sway those NIST staff who are discouraged from taking on such assignments.

There is potential to grow NIST programmatic activities in areas where Congress and the Administration are seeking to thwart a threat of losing U.S. leadership or competitive advantage. With a proactive role in defining the scope of work and a willingness to take a calculated risk in assuming additional responsibilities, NIST could potentially leverage interest in emerging areas among Congressional and Administration leaders. Such risks may require NIST to assume some financial burden and, consequently, would require NIST leaders to make difficult decisions about reductions in existing programs.

Congress and the Administration are currently showing strong interest in the way in which the U.S. approaches standardization, particularly for emerging technologies such as artificial intelligence, assurance and confidence in the security of IOT devices, connected and autonomous vehicles and blockchain technologies. The cross-cutting nature of these technologies and their applications is of interest to Committees in Congress that do not conduct oversight of NIST (e.g., House Energy and Commerce, House Armed Services, Senate Homeland Security and Government Affairs, etc.) and in EOP offices with which NIST has not traditionally engaged (e.g., Council of Economic Advisors, Domestic Policy Committee, etc.). Proactive engagement with staff and leadership of these Committees and offices can help communicate how NIST's products and services help address their interests while providing long-term value for NIST. 


\section{Technology and Science Landscape}

\subsection{Major Technology Drivers}

Various influential technologies are currently in the mainstream but still require further advancement. These technologies form the foundation for future innovation in cybersecurity, sustainable energy, precision medicine, smart cities, autonomous vehicles, human augmentation, next generation communication, artificial intelligence, quantum science, internet of things, and blockchain.

\subsubsection{Security Background}

The notion of "securing our digital experience" refers to users and providers implementing good digital practices to reduce the frequency and impact of malware attacks and quicken recovery when attacks happen. Whether it is the inadvertent release of personal information, unintended access to secure systems, botnet denial-of-service attacks or insider threats, there is an acknowledged need to improve and prepare for the security issues of tomorrow. Some of the more high profile online security issues include [55]: (1) the Equifax breach that gave cybercriminals access to the personal data of 145 million people; (2) the 2013 hack of Yahoo's 3 billion accounts as announced by Verizon; (3) the leak by Shadow Brokers of a suite of hacking tools believed to belong to the National Security Agency (NSA); (4) the WannaCry attacks that spanned 150 countries and targeted businesses running outdated windows software and locked down computer systems; and (5) the Computer virus NotPetya that targeted Ukrainian businesses using compromised tax software which spread to FedEx, WPP, Rosneft, and Maersk.

\section{Implications for NIST}

NIST is held in high regard for its role in securing non-classified federal systems, particularly through the development and ongoing enhancements to the Cybersecurity Framework (CSF) in response to Executive Order 13686 and $13800^{3}$. It is likely that NIST's ownership of, and thus responsibilities to maintain, improve, and expand the CSF will continue for years to come. Looking forward, the promise of quantum technologies requires vigilance in developing quantum-resistant cryptography to protect systems of the future.

Security is often tied closely to data privacy. While the two are related, there are some important differences. NIST expertise in computer security is also being called upon to help develop privacy engineering tools. The EU's adoption of the GDPR makes it likely that the U.S. will have a privacy framework of its own, and NIST may be asked to play a role in the development of such a framework.

\subsubsection{Sustainable Energy Innovations Background}

Sustainable energy is a global phenomenon on the upswing and holds the key to solving many of the world's energy challenges. The adoption of sustainable energy can dramatically reduce emissions that contribute to global warming emissions, improve public health, and

\footnotetext{
${ }^{3}$ https://www.whitehouse.gov/presidential-actions/presidential-executive-order-strengthening-cybersecurity-federal-networks-criticalinfrastructure/
} 
provide jobs and other economic benefits. For the foreseeable future, the usage of sustainable energy is predicted to increase, but current priorities and decisions will determine how future societies benefit.

A study by the Department of Energy’s National Renewable Energy Laboratory (NREL) [56] predicts that the U.S. can generate $80 \%$ of its electricity needs from renewable energy by 2050. The sustainable energy innovation challenge requires a systemic and multi-stakeholder approach to help bring a broader set of nascent technologies to technical and commercial maturity. Public funding programs will provide much-needed early support to these nascent technology areas in the form of research, development and demonstration (RD\&D), research infrastructure and interdisciplinary and multi-stakeholder collaboration.

Despite a recent surge in investments and the evolution of enabling policy instruments, clean energy RD\&D initiatives are still lacking while significant barriers to innovation remain. RD\&D funding levels lag compared to other sectors such as information technology. Additional focus on market deployment can be achieved by accelerating sustainable energy innovation and promoting innovation across the energy value chain. Moreover, long-term and mission programs, similar to the Japanese hydrogen program [57] and the Danish wind energy program [58], are more likely to offer systemic breakthroughs as well as a competitive edge to the U.S.

One key to smart energy use is possessing the capacity to optimize grid operations. Electrical devices must be able to communicate their operating status, collect information on grid conditions and respond in ways that most benefit their owners and the grid. Constant interactions of millions of smart agents will optimize the grid, creating a collaborative network nearly as complex as a biological system. The future of renewable energy is also digital. For example, a digital wind farm will be able to collect, visualize and analyze unit and site level data. Through the constant collection of this data - weather, component information, service reports - a predictive model is built, and data is turned into actionable insights. These models will serve as the basis for new suites of applications, allowing wind farm operators to optimize maintenance strategies, improve reliability and availability and increase annual energy production.

\section{Implications for NIST}

Access to accurate, internationally recognized measurements and standards is required for implementation of renewable energy and climate change-related policies around the globe. These measurements and standards are critical for both policy development as well as evaluating the impact of mitigation efforts.

The following are examples of related emerging technology areas that would benefit from NIST mission programs and expertise:

1. Concentrated solar photovoltaics (CSP), photovoltaic transparent glass and spacebased solar power offer new opportunities to leverage the Sun's energy.

2. Biofuel technologies, including cellulosic ethanol and biodiesel from microalgae, promise to produce conventional fuel-compatible energy at low or zero greenhouse 
gas emissions. Genetic modification of organisms can produce new fuels by unconventional means.

3. Micro-nuclear reactors offer a small, sealed version of a nuclear reactor (approximately a few tens of meters in length) and are capable of being shipped or flown to a site.

4. Thorium provides a new alternative for fuel in a nuclear reactor and be used to produce fuel in a breeder reactor. Thorium produces 10 to 10,000 times less longlived radioactive waste than current materials and comes out of the ground as a $100 \%$ pure, usable isotope that does not require enrichment.

5. Hydrogen fuel (the use of hydrogen gas $\left(\mathrm{H}_{2}\right)$ as an energy carrier) acts as a zeroemission fuel when burned with oxygen. It can be used in electrochemical cells or internal combustion engines to power vehicles, electric devices, or spacecraft. This is an area of current research, and new developments and technologies are causing this field to evolve rapidly.

NIST's roles in security, sensors, materials, engineering, best practices, guidelines and standards are all relevant to progress in sustainable energy. There are clear roles for NIST to play, as industry is not waiting and is working within the constraints of current policies to develop and deploy innovative energy solutions.

\subsubsection{Health Background}

One of the most fascinating aspects of public health is the ways in which it changes over time. Health concerns of the early part of the $20^{\text {th }}$ century are quite dissimilar to the concerns of the $21^{\text {st }}$ century. However, the goals of those studying and working in the field are a constant: better health for more people.

Nearly half of the top 10 emerging technologies highlighted by the World Economic Forum in 2014 and 2015 were related to healthcare or would impact healthcare in a significant manner [59]: next-generation robotics, precise genetic-engineering techniques, emergent artificial intelligence, digital genome, body-adapted wearable electronics, human microbiome therapeutics, RNA-based therapeutics, the quantified-self (predictive analytics) and braincomputer interfaces. In 2017, genomic vaccines, the human cell atlas, and liquid biopsies made the World Economic Forum top 10 list [60].

Precision medicine is an emerging approach for disease treatment and prevention that considers individual variability in genes, environment and lifestyle for each person. Many of the technologies needed to meet the goals of the precision medicine initiative are in the early stages of development or have not yet been developed. Though nascent, the precision medicine industry is evolving into a lucrative enterprise. The global market is forecasted through 2022 at nearly \$2.5 billion at a Compound Annual Growth Rate (CAGR) of 11.8\% and the global companion diagnostics market is predicted to reach $\$ 5.6$ billion by 2019 at a CAGR of $18.1 \%$ [61].

Digital public health (DPH) is a re-imagining of public health processes by blending established public health wisdom with new digital concepts and tools. One aspect of DPH that is markedly changing is that of data surveillance. Electronic data collection systems, the 
driver of big data for health, have made public health surveillance increasingly extensive and complex. While it may be tempting to believe that technology can mitigate health threats, today human expertise is still essential in the diagnosis of disease, data interpretation, communication and more to ensure that the public's health is protected. Regardless, the data revolution is changing healthcare into a data-driven industry.

The healthcare industry has access to a wealth of data from wearable devices such as Fitbit, and to online analytics tools such as those available on Google. Smartphones and cloudbased solutions can store and provide access to health information, from blood pressure to full medical records. Personal device solutions allow individuals to continuously monitor lifestyle-related behaviors such as diet and physical activity while providing early diagnostics and treatment compliance. Smartphones support virtual consultations, remote diagnostics and monitoring and can manage health claims and prescriptions.

When individual data is aggregated, cloud-based solutions become more useful "medical instruments” for doctors and all healthcare workers across high- and low-income regions. Using data and analytics tools, doctors can determine what factors keep people healthy, rather than what makes them unhealthy [62]. Machine learning algorithms are used for genomic sequencing and to analyze and draw inferences from the vast amounts of data taken from patients and healthcare institutions. AI techniques are used in precision cardiovascular medicine to understand genotypes and phenotypes in existing diseases, improve the quality of patient care, enable cost-effectiveness and reduce readmission and mortality rates.

All of this additional electronic data does create risks, including the potential for healthcare providers to become high-value targets for cyber-attacks, leading to increased expenditures in the cybersecurity area

\section{Implications for NIST}

Many of the issues raised above can benefit from a measurement infrastructure that provides assurance of biomedical research results and confidence in clinical decision-making, such as analytical tools and associated reference data/materials that NIST could provide.

NIST's current activities put the agency in a position to make immediate contributions in several areas. For instance, NIST can help address inconsistent standards for genomic tests. Current genomic diagnostic tests are evaluated for their "clinical utility," a metric that is neither clear nor predictable. Objective and reliable standards for the evaluation processes are needed for genomic tests to be broadly accepted. Future advances in molecular profiling, combined with genetic clinical information, promise unprecedented advances in precision medicine, but will require precision measurements, an area in which NIST excels. Data privacy policies and technologies are areas that NIST could also help address.

\subsubsection{Smart Cities and Communities Background}

Smart city technologies promise benefits to diverse sectors, from transportation and energy to agriculture and public safety. They provide the ability to manage resources in a way that is both sustainable and increasingly inexpensive, benefiting both people and the world at large. 
Successful smart cities of the future will combine the best solutions based on the Internet of Things (IoT)/Cyber-Physical Systems (CPS), physical sensors, and big data. The projections of the scale and economic value of these technologies are very optimistic [63].

Smart city technologies will pervade almost every aspect of modern living. For instance, large amounts of information can be ingested and studied to identify where energy waste is occurring and where improvements can be made. For example, sensors will allow cities to monitor and measure city water systems to identify any leaks or blockages that affect water pressure and flow. Expectations are that 2030 will bring the introduction of connected street lights, which will stream data between millions of devices and provide a backbone to improve city services such as light, traffic, air quality, public safety and parking. Lighting technology will be at the heart of urban life, helping deliver more sustainable and betterconnected smart cities.

\section{Implications for NIST}

The emerging smart city area represents the importance and growth of systems engineering, communications and software/algorithms. The goal is to design and deploy IoT and smart city solutions that are replicable, scalable and sustainable, supported by the identification and adoption of a consensus framework for smart city technologies. NIST scientists and engineers will play important roles in addressing many smart city challenges, especially those that call on NIST's expertise and leadership in areas such as standards and interoperability, measurement and metrics and testing and certification. In addition, NIST should expect inquiries about how standards and standardized approaches can help increase user confidence in these technologies.

\subsubsection{Drones and Autonomous Vehicles Background}

Drones have the potential to increase efficiency across a wide range of applications, from terrain mapping to agriculture. Perhaps the most beneficial use of drones will be in dangerous and hazardous operations, such as disaster assessment, to reduce or even eliminate human exposure to danger. Future developments in drone technologies, including improvement in hardware, miniaturization and advances in software, might enable surprising new uses for drones. As technology enablers increase drones' versatility and flexibility, drones might find use not only as stand-alone products but also as features for systems of solutions. Still limited by their human controllers, the next generation of drones will be powered by artificial intelligence. AI will allow drones and other vehicles to make decisions and operate themselves "autonomously" on the behalf of their human controllers.

The autonomous vehicle has attracted a great deal of interest (including skepticism), as well as research and development investments. As a personal transportation vehicle, it is unclear how practical or affordable autonomous vehicles will be, whether and when they will become mainstream and what the unintended consequences will be (e.g., impact on the trucking industry). A study by McKinsey Consulting [64] predicted that up to $15 \%$ of new automobile industry vehicles sold by 2030 could be fully autonomous. Fully autonomous vehicles will require advanced, multiple-sensor technologies to stay on the road, avoid collisions and obey traffic laws. 
Currently, autonomous vehicles use a combination of ultrasonic, radar, image and Lidar sensors to help them "see" where they are going [65]. There are still technological barriers to fully integrating the range of sensors and software needed to achieve a fully autonomous car. Some of the software challenges include object detection, object analysis, human-like decision making and fail-safe mechanisms that allow a car to fail without putting its passengers or people around it in danger.

The perception of drones and autonomous vehicles will change, for better or worse, as machine learning and AI techniques mature and impacts begin to be realized. If and when a machine gains the capacity to make decisions and "learn" to function independently of humans, the potential benefits must be weighed against the possible harm that could befall entire societies as the human input is removed from the robot behavior.

\section{Implications for NIST}

Prior to fully-realized commercialization, autonomous vehicles and drones will face technological, measurement and standardization hurdles. Many of the issues raised above will benefit from a measurement infrastructure that can provide assurance and confidence in autonomous systems such as cars. Areas in which NIST may be asked to contribute include: fundamental research in wireless co-existence and spectrum sharing, development of documentary standards to address interoperability and performance characteristics, data security issues, improved sensors and actuators, and evaluation of key performance metrics.

\subsubsection{Human Augmentation Background}

The term "human augmentation" is generally used to refer to technologies that enhance human productivity or capability, or that somehow add to the human body. Aided by augmentation technology, the future human will be stronger, faster, less prone to injury and more productive. An increasingly wide range of technologies across very different disciplines are enabling human augmentation, from bioengineering to robotics to mechatronics to AI.

One frontier for augmentation is that of body integrated sensors that would continuously monitor a person's state of health (e.g., nerves, muscles and organs), creating a human intranet. In addition, human augmentations are being pursued to end physical disabilities through bionics and prosthetics with brain-computer interfaces. For example, powered exoskeleton technology, which can aid workers in carrying heavy loads, has been shown to enable paraplegics to walk again.

\section{Implications for NIST}

As human augmentation begins to permeate many aspects of life, the need for advancements in the wide range of associated technologies may lead to an international competition in science and research. An international race to achieve leadership in human augmentation will potentially lead to a competitive environment like the $20^{\text {th }}$ century Space Race, which resulted in the rapid development of a wide range of new technologies. Some technologies associated with human augmentation include human genetic engineering, gene therapy, 
neural implants, brain-computer interfaces, nanomedicine, and 3D bioprinting. To accelerate the acceptance and use of these technologies, there must be standard test methods to evaluate their safety and performance. NIST contributions may come from its deep experience in industrial robotics, advanced materials, electronic engineering, battery systems, artificial intelligence and cybersecurity. Better standards also foster competition by allowing manufacturers, including new startups, to demonstrate the performance of their products using agreed-upon metrics. NIST can play a role as a neutral party, providing technical guidance and leadership in standards development while helping industry safely extend human performance.

\subsubsection{G and Next-Generation Communication Background}

Next-generation telecommunications networks (5G) are expected to hit the market by 2020. Beyond just speed improvements, 5G is expected to unleash a massive IoT ecosystem (including smart cities noted above), where networks can meet communication needs for billions of connected devices with exponential improvements in speed, latency and data volume. Key features of 5G include high throughput, low latency, high mobility and high connection density. The widespread use of $5 \mathrm{G}$ technologies is expected to produce $\$ 3.5$ trillion in output and 22 million jobs globally by 2035 [66]. However, technical impediments still stand in the way. Use cases for 5G will bring new requirements on storage, computation and network domains, and will introduce new risks to the confidentiality, integrity and availability of enterprise and user data.

\section{Implications for NIST}

For the design, evaluation and deployment of future 5G networks, it is essential to have a 5G channel model that is well supported by diverse measurements across different frequency bands, deployment scenarios, as well as geographical areas. The 5G mm Wave Channel Model Alliance led by NIST provides a venue to promote fundamental research into measurement, analysis, identification of physical parameters and statistical representations of millimeter-wave propagation channels. This alliance has brought together more than 130 participants to solve the most pressing modeling and measurement challenges facing the deployment of $5 \mathrm{G}$ wireless communications. The output of this alliance will be incorporated into new standards, specifications and best practices benefitting the entire industry. As a national leader in cybersecurity, NIST will be asked to take a lead role in helping to secure this massive IoT ecosystem. Congress and the Administration's concerns about Chinese influence in 5G technologies and 5G standards development may lead to calls for NIST experts to increase their participation and assume leadership roles in the development of 5G standards, including for aspects such as the security of 5G systems.

\subsection{Cross-Cutting Emerging Technologies}

Beyond the noted technology drivers, new, cross-cutting technology capabilities are emerging that will likely shape our future. For instance, artificial intelligence and quantum science are two disruptive technologies expected to influence, enhance or otherwise provide the springboard for innovation across multiple technology disciplines. Foreign governments such as China are investing billions of dollars in infrastructure projects, workforce training and research to "win" the race to AI and/or quantum supremacy. 
Similarly, technologies that drive the IoT and blockchain emerging architectures are ready to support system implementations in new, large-scale application environments. IoT connects systems and devices to people in ways that will drastically change the landscape of many sectors (e.g., transportation industry with autonomous cars, manufacturing with automated supply chains and public safety with connected first responders). Blockchain has quickly established itself as one of the world's leading software platforms for digital assets.

\subsubsection{Artificial Intelligence Background}

A term first coined in 1956, modern day Artificial Intelligence (AI) refers to computers performing tasks that normally require human intelligence such as vision, speech or decisionmaking. As computing technologies have matured, the meaning of AI has evolved. Today AI encompasses specific computer architectures, programming languages, and algorithmic approaches, geared toward extracting knowledge from data and providing or acting on a decision based on that knowledge. While often labeled as an emerging technology, AI is somewhat distinct in that it is also actively applied in research and practice. Game play, anomaly detecting, question answer, search and drawing complex insights from massive amounts of data are just a few active AI applications.

\section{AI Quick Facts:}

$>$ The term “artificial intelligence" first coined by John McCarthy in 1956.

$>$ IBM's AI machine Deep Blue became the first chess machine to beat the world chess champion in 1997.

$>$ While only 33\% of consumers think they use AI-enabled technology, $77 \%$ actually use an AIpowered service or device [67].

> By 2030 AI will contribute and estimated \$15.7 Trillion to the global economy [68].

According to IEEE [69], activity surrounding the development of international AI-related standards are on the rise, including standards for areas such as ethics for AI and malicious use of AI. The implications and capabilities of different machine learning (deep learning) algorithmic approaches are under investigation. New computational hardware, designed to mimic the human brain, is also under development.

\section{Implications for NIST}

There are clear roles for NIST in developing the measurement science and security for AI. Measurement techniques are needed for training data best practices, model accuracy, model strength, system accuracy, privacy (data protection) and malicious intrusion. It is important that NIST is viewed as the government expert for measurement across the AI spectrum (datato-application). This position can be supported by maintaining NIST visibility in appropriate standards groups and participation in other agency projects. NIST's progress in measurement standards development and cultivating trust in AI has the potential for far reaching impacts on future AI innovation. The high-speed, fast-paced world of AI technology development requires that NIST carefully choose its roles. Selected properly, NIST can have a significant positive societal impact and efficient government mission delivery without stifling the rapid acceleration of industry innovation. 
Workforce issues are critical when developing AI competency. To realize impact, NIST staff will require the appropriate skillsets needed to measure, use and advise on issues of machine learning, deep learning, natural language processing and machine vision. NIST (and the government at large) will likely have difficulties competing with industry for top U.S. talent in the AI field due to high demand and government salary limitations.

\subsubsection{Quantum Information Science and Technology Background} Quantum Information Science (QIS) is an area of study that bases information science on quantum effects in physics. QIS encompasses theoretical issues in computational models as well as more experimental topics in quantum physics, such as what can and cannot be done with quantum information units known as Qubits. Quantum technology is a new field of physics and engineering that transitions some of the properties of quantum mechanics, especially quantum entanglement, superposition and tunneling, into practical applications such as quantum computing, sensors, cryptography and simulation. The race for quantum supremacy is a race for secure communications, unimaginable computational power and the ability to defeat all modern-day cryptography techniques. When finally realized (estimated in 10 to 15 years), the arrival of a truly quantum computer has the potential to be a disruptive technology with unprecedented implications. In August 2017, China used a quantum satellite to transmit potentially unhackable data, achieving "spooky action” (quantum entanglement) at a record distance - a possible sign that the U.S. is falling behind in the quantum race. Over the past few years, breakthroughs in Qubit entanglement has dominated the research. Qubit entanglement allows the ability to control polarization of a single photon, enabling faster computers and harder codes for hackers to decrypt.

Quantum computing has seen R\&D progress in academic and corporate sectors and will likely play a significant role in future encryption standards, practices, and code-breaking methods. Companies developing quantum computing technology include Google, IBM, and D-Wave Systems [70]. While it is often stated that a practical quantum computing solution is 10 to 15 years out, the amount of industry and government R\&D investment in the field may result in realization of a quantum world much sooner than that.

\section{Quantum Quick Facts:}

$>$ Quantum computing uses quantum-mechanical phenomena, such as superposition and entanglement, to process information.

$>$ Quantum supremacy is achieved when quantum computing devices can solve problems that classical computing cannot, expected to occur in the next few years.

$>$ Future quantum computers could potentially be millions of times more efficient than today's computers.

$>$ U.S. and European companies are the primary suppliers of quantum metrology and sensing technologies to the world market [71].

$>$ Quantum computing market is projected to surpass \$5 billion through 2020 [72].

Near-term opportunities in quantum science remain mostly in the theoretical and foundational research realm, including continuing to expand single particle quantum measurements and technologies, leveraging quantum properties of macroscopic objects, and 
developing quantum many-body physics, measurements and technologies. Applications and impacts of quantum science are broad and span the development of smaller, cheaper sensors that can be used in infrastructure, advanced imaging and detection, modeling and simulation of highly complex systems, solutions for computationally intractable problems and cybersecurity.

\section{Implications for NIST}

It is likely that the most far-reaching quantum technologies have not yet been anticipated and will emerge only as basic research continues to mature and develop. Regardless of the applications of this technology, there will be a need for precise measurements at quantum scales. NIST's measurement science role will be critical and foundational to the research and development needed to grow this area, and the measurement tools developed by NIST will be essential in enabling the engineering of functional quantum systems.

NIST is not new to quantum technologies and has developed a strong foundation on which to build. NIST has remained forward thinking with its work to build a quantum clock and ongoing facilitation of research into quantum cryptography. NIST is currently viewed as a leader in basic research in this field. Staying connected to industry other government efforts in quantum is important to ensure maintained leadership.

\subsubsection{Internet of Things \\ Background}

"Internet of Things" (IoT) can be a widely encompassing phrase. For this discussion, references to IoT will include the "Industrial Internet of Things," and/or "Cyber-Physical Systems.” IoT is best thought of as a system architecture that connects systems (or devices) to humans. The three pillars of IoT are connectivity, interoperability, and security. IoT technologies overlap with those discussed in the previous sections of Smart Cities and NextGeneration Communication.

IoT Quick Facts:

$>$ In 2015 there were about 15.4 billion connected devices.

$>$ By 2020 the number is expected to grow to 30.7 billion.

$>$ By 2025, 75.4 billion.

$>$ In 2016 global spending on the IoT across markets was $\$ 737$ billion.

$>$ By 2020 the number is expected to reach $\$ 1.29$ trillion.

$>$ IoT saves money too. The city of Barcelona saves $\$ 37$ million a year due to smart lighting.

IoT is the next technology mega-trend, providing outstanding opportunities and challenges for companies, governments and consumers alike. When IoT is smartly incorporated with Big Data and AI, resulting applications can be very intelligent, predictive, collaborative and even autonomous. In other words, the Internet of Things is about the transformation of any physical object into a digital data product. Once you attach a sensor to it, a physical object starts functioning a lot like any other digital product: It gives data about its usage, location and state. With support from cloud-based applications, IoT devices can be tracked, controlled, personalized and upgraded remotely. With the advent of IoT, society is moving 
towards smart cities, smart houses and smart living. Everything on earth will be connected as society becomes an IoT world.

The Internet of Things requires cloud-based applications to interpret and transmit the data coming from sensors. IoT security is a growing concern as new exploits are used along with botnet collectives such as the Mirai malware for a distributed denial of service (DDoS) [73] and other attacks. Weak security practices from manufacturers including weak hardcoded default passwords and infrequent security/firmware updates have made IoT devices increasingly vulnerable to sophisticated attacks.

\section{Implications for NIST}

The IoT ecosystem presents NIST with numerous opportunities. Advances are needed in connectivity through next-generation networks and antennas, spectrum sharing, coexistence without interference and light-weight, low-power, flexible sensor/materials. Advances in interoperability will require consensus standards. Secure IoT is required to protect IoT reliability, data privacy and system accuracy.

NIST expertise in the technologies that underpin IoT architectures and applications dates back many decades, but the NIST response to the interest in IoT is relatively recent. Given the multi-disciplinary nature of IoT, elements of IoT related research are underway in most NIST laboratories. To maximize impact, NIST will need a strategy that relies on complementary efforts to create a coordinated response.

IoT is an example of how NIST maintains broad impact by underpinning foundational-level technologies and thus makes semi-transparent contributions to industry's roll-out of IoT solutions. NIST's work with industry and academia can help build consensus towards best practices of IoT security and performance measurements, regardless of the IoT solution space.

\subsubsection{Blockchain Background}

Best known for enabling Bitcoin ${ }^{4}$ and similar cryptocurrencies, blockchain is a technology sometimes described as a secure distributed ledger. Decentralized consensus is the backbone of blockchain. Once a new blockchain data record (a block) is recorded, it cannot be manipulated without manipulating all subsequent blocks, which would require collusion of the network. As there are many variations in the implementations of blockchain technologies, not all are created equal. In recent months the "un-hackable" blockchain has been hacked several times (Verge, April 2018 [74] ; Coinrail, June 2018 [75]). Blockchain is often referenced as suitable for recording of events, medical records and other record management activities including identity management, transaction processing, documenting provenance, food traceability and voting. Blockchain is considered by many to be a foundational technology (rather than a disruptive one) with widespread implications.

\footnotetext{
${ }^{4}$ https://bitcoin.org/en/
} 


\section{Blockchain Quick Facts:}

> Blockchain technology has managed and distributed more than $\$ 270$ billion in transactions.

> Over the last 5 years, venture capitalists have invested more than $\$ 1$ billion into blockchain companies.

$>$ Ninety percent of major North American and European banks are exploring blockchain solutions.

Blockchain's market size was \$708 million in 2017.

$>$ Blockchain's market size is expected to be $\$ 60$ billion by 2024 .

The largest drawback of blockchain is that the vetting of the blocks is computationally (and thus energy) intensive. Mining cryptocurrencies such as Bitcoin is extremely expensive given the way these blockchain implementations currently operate. Morgan Stanley estimates that mining the blockchain that underpins Bitcoin will use around $125 \mathrm{TWh}$ (Terawatt hours) of energy in 2018, an amount that is on par with Argentina's projected annual electricity consumption for the year [76].

\section{Implications for NIST}

As NIST collaborates with experts from industry, academia and government to strengthen its blockchain-associated research portfolio ${ }^{5}$, several areas of opportunity become clear, namely cryptography, quantum computing (detailed previously), hash functions and consensus standards for blockchain.

Efforts that may advance underlying blockchain technologies include support for advancements in quantum computing. In the context of quantum computing, the public key cryptographic algorithms used within most blockchain technologies for public/private key pairs will need to be replaced when powerful quantum computers become a reality. NIST has a role in helping prepare for this reality.

Much of NIST's blockchain contributions will relate to how elements of the technology are managed. Cryptographic key management support is important because blockchains are not centralized and there is no intrinsic, central place for user key management, an area where NIST could contribute. NIST already provides assistance for blockchain identification, as blockchain technologies take a list of transactions and create a hash "fingerprint" for the list. Requirements for hashing algorithms used by Bitcoin, Ethereum, and Litecoin are described in NIST Federal Information Processing Standards (FIPS) publications FIPS PUB 180-4: Secure Hash Standards (SHS) and FIPS PUB 202: SHA-3 Standard: Permutation-Based Hash and Extendable-Output Functions.

In the context of blockchain standardization (and standardization in general), NIST is tasked with the role of encouraging and coordinating federal agency use of voluntary consensus standards in lieu of government unique standards. NIST is actively participating in consensus-based, documentary standard development efforts and has been tasked with mobilizing federal agency participation as well. Given that blockchain is an agnostic technology, NIST and industry can work together to promote secure blockchain use across sectors such as health records, voting and e-commerce for the betterment of society.

\footnotetext{
${ }^{5}$ NIST hosted the IEEE Blockchain Summit in Gaithersburg September 18-19, 2018 (http://sites.ieee.org/blockchainsummit/)
} 


\section{Conclusion}

The contents of the 2018 National Institute of Standards and Technology Environmental Scan provides insight into a breadth of factors that may potentially influence NIST and its mission, either positively or negatively, as the agency looks to create a strategic plan for the coming years. The exercise was conducted through four separate lenses: Societal, Political, Geopolitical, and Technological. Observations highlighted range for the unique political climate NIST currently faces to challenges to NIST's leadership in metrology to the new opportunities provided new breakthrough technology innovations. Some conclusions that may be reached from this scan include:

- As the NIST workforce ages, new generational gaps may create challenges in communication and achieving mutual understandings.

- The combination of STEM talent pool shortages and strict citizenship requirements will continue to affect NIST's ability to hire qualified individuals.

- Women and minorities are still underrepresented in the NIST scientific workforce.

- General skepticism affects the collegial and collaborative spirit of NIST employees.

- Declining levels of institutional investment and continued instability affects the ability of NIST to maintain long-term core competencies in metrology.

- Immigration reform and evolving international relationships may affect NIST's future ability to work with the world's most talented scientists.

- Mandated involvement in new standards and related activities without new funding can affect NIST's stature on the international stage as well as NIST's ability to provide continuous support of ongoing standards activities.

- Budget uncertainties affect staff morale and productivity, particularly as they relate to ongoing threats of program reduction or elimination.

- A general lack of understanding of NIST's role by congressional staff affects NIST's ability to leverage interest in emerging areas where NIST could play an important role.

\section{Acknowledgments}

Special thanks to Joannie Chin, Laura Espinal and Simon Frechette for providing thoughtful comments and improving the quality of this manuscript.

\section{Disclaimer}

Certain commercial equipment, instruments, or materials are identified in this paper in order to specify the experimental procedure adequately. Such identification is not intended to imply recommendation or endorsement by the National Institute of Standards and Technology, nor is it intended to imply that the materials or equipment identified are necessarily the best available for the purpose. 


\section{Bibliography}

[1] U.S. Census Bureau, 13 March 2018. [Online]. Available: https://www.census.gov/newsroom/press-releases/2018/cb18-41-populationprojections.html.

[2] Alzheimer's Association, "2018 Alzheimer's Disease Facts and Figures," 20 March 2018. [Online]. Available: https://www.alz.org/facts/.

[3] Pew Research Center, "FACTANK: News in the Numbers," 11 April 2018. [Online]. Available: http://www.pewresearch.org/fact-tank/2018/04/11/millennials-largestgeneration-us-labor-force/ft_18-04-02_genworkforcerevised_bars1/.

[4] R. Fry, R. Igielnik and E. Patten, "How Millennials today compare with their grandparents 50 years ago," 16 March 2018. [Online]. Available: http://www.pewresearch.org/fact-tank/2018/03/16/how-millennials-compare-withtheir-grandparents/.

[5] Panel on the Economic and Fiscal Consequences of Immigration, "The Economic and Fiscal Consequences of Immigration," The National Academies Press, Washington, DC, 2017.

[6] B. Hoban, "Brookings Institute," 24 August 2017. [Online]. Available: https://www.brookings.edu/blog/brookings-now/2017/08/24/do-immigrants-steal-jobsfrom-american-workers/.

[7] J. McCarthy, "Americans More Positive About Effects of Immigration," 28 June 2017. [Online]. Available: http://news.gallup.com/poll/213146/americans-positive-effectsimmigration.aspx.

[8] J. Gramlich, "www.pewresearch.org," 28 December 2017. [Online]. Available: http://www.pewresearch.org/fact-tank/2017/12/28/10-things-we-learned-about-genderissues-in-the-u-s-in-2017/.

[9] M. Holmes, "Society of Women Engineers," Spring 2016. [Online]. Available: http://www.nxtbook.com/nxtbooks/swe/spring16/index.php\#/12.

[10] R. Noonan, "Women in STEM: 2017 Update," 13 November 2017. [Online]. Available: http://www.esa.doc.gov/sites/default/files/women-in-stem-2017-update.pdf.

[11] C. Manibog and S. Foley, "Financial Times," 10 August 2017. [Online]. Available: https://www.ft.com/content/c8d1d150-7869-11e7-a3e8-60495fe6ca71. 
[12] Z. Qureshi, "Brookings Institute," 16 February 2018. [Online]. Available: https://www.brookings.edu/blog/up-front/2018/02/16/globalization-technology-andinequality-its-the-policies-stupid/.

[13] R. Kochhar and A. Cilluffo, "Pew Research Center," 1 November 2017. [Online]. Available: http://www.pewresearch.org/fact-tank/2017/11/01/how-wealth-inequalityhas-changed-in-the-u-s-since-the-great-recession-by-race-ethnicity-and-income/.

[14] K. Parker, J. Menasce Horowitz, A. Brown, R. Fry, D. Cohn and R. Igielnik, "Pew Research Center Social and Demographic Trends," 22 May 2018. [Online]. Available: http://www.pewsocialtrends.org/2018/05/22/what-unites-and-divides-urban-suburbanand-rural-communities/.

[15] J. A. Delreal and S. Clement, "New poll of rural Americans shows deep cultural divide with urban centers," Washington Post, 17 June 2017.

[16] A. L. Schmidt, F. Zollo, M. Del Vicario, A. Bessi, A. Scala, G. Caldarelli, H. E. Stanley and W. Quattrociocchi, "Anatomy of news consumption on Facebook," Proceedings of the National Academy of Sciences of the United States of America, pp. 3035-3039, 2017.

[17] Y. Gorodnichenko, T. Pham and O. Talavera, "Social media, sentiment and public opinions: Evidence from \#Brexit and \#USElection," Swansea University, 2018.

[18] Bloomberg, "How Faking Videos Became Easy — And Why That's So Scary," Fortune, 11 September 2018. [Online]. Available: http://fortune.com/2018/09/11/deepfakes-obama-video/.

[19] R. Botsman, "The Guardian," 10 February 2018. [Online]. Available: https://www.theguardian.com/commentisfree/2018/feb/11/dawn-of-the-techlash.

[20] A. Ward, K. Duke, A. Gneezy and M. Bos, "Brain Drain: the Mere Presence of One's Own Smartphone Reduces Available Cognitive Capacity," Journal of the Association for Consumer Research, pp. 140-154, April 2017.

[21] National Highway Traffic Safety Administration, "United State Department of Transportation," 6 October 2017. [Online]. Available: https://www.nhtsa.gov/pressreleases/usdot-releases-2016-fatal-traffic-crash-data.

[22] B. Primack, A. Shensa, M. Sidani, E. Whaite, L. Lin, D. Rosen, J. Colditz, A. Radovic and E. Miller, "Social Media Use and Perceived Social Isolation Among Young Adults in the U.S.," American Journal of Preventive Medicine, pp. 1-8, July 2017.

[23] R. Edmonds, "Strategic Business Insights," May 2018. [Online]. Available: http://www.strategicbusinessinsights.com/explorer/BGD/BGD-2018-05.shtml. 
[24] H. Sutcliffe and C. von Kameke, "World Economic Forum," 16 January 2018. [Online]. Available: https://www.weforum.org/agenda/2018/01/embrace-the-tech-backlash/.

[25] Edelman Trust Barometer, "2018 Edelman Trust Barometer," 2018. [Online]. Available: http://cms.edelman.com/sites/default/files/201802/2018_Edelman_Trust_Barometer_Global_Report_FEB.pdf.

[26] J. Beck, "The Atlantic," 24 June 2017. [Online]. Available: https://www.theatlantic.com/science/archive/2017/06/the-challenge-of-fightingmistrust-in-science/531531/.

[27] T. Erickson, "The Four Biggest Reasons for Generational Conflict in Teams," Harvard Business Review, 16 February 2009.

[28] E. McEntarfer, "U.S. Census Bureau," April 2018. [Online]. Available: https://www.census.gov/library/stories/2018/04/aging-workforce.html.

[29] Y. Xue and R. C. Larson, "Bureau of Labor Statistics," Nat 2015. [Online]. Available: https://www.bls.gov/opub/mlr/2015/article/stem-crisis-or-stem-surplus-yes-andyes.htm\#_edn8.

[30] P. Hernandez, "What Others Say About NIST," 2017. [Online]. Available: https://www.nist.gov/pao/what-others-say-about-nist. [Accessed 2018].

[31] J. Kavanagh and M. D. Rich, "Truth Decay: An Initial Exploration of the Diminishing Role of Facts and Analysis in American Public Life," RAND Corporation, Santa Monica, California, 2018.

[32] R. Lyons, "Forbes," 15 March 2018. [Online]. Available: https://www.forbes.com/sites/richlyons/2018/03/15/in-an-era-of-distrust-here-are-threeways-to-transform-your-organization/\#58e4a08ffe12.

[33] A. Bryant, "The New York Times," 27 October 2017. [Online]. Available: https://www.nytimes.com/2017/10/27/business/how-to-be-a-ceo.html.

[34] G. Tassey, "Globalization of technology-based growth: The policy imperative," The Journal of Technology Transfer, vol. 33, no. 6, pp. 560-578, 2008.

[35] OECD, "Release of Main Science and Technology Indicators - Latest estimates of R\&D investment in OECD," 2018.

[36] OECD Data Brief, "www.oecd.org," February 2018. [Online]. Available: https://www.oecd.org/sti/DataBrief_MSTI_2018.pdf. 
[37] National Science Board, "Science \& Engineering Indicators 2018," 2018. [Online]. Available: https://www.nsf.gov/statistics/2018/nsb20181/report/sections/overview/r-dexpenditures-and-r-d-intensity.

[38] American Institute of Physics, "FYI Science Policy News from AIP," 8 November 2016. [Online]. Available: https://www.aip.org/fyi/2016/us-rd-spending-all-time-highfederal-share-reaches-record-low.

[39] J. Burr, "Federal Times," 31 January 2018. [Online]. Available: https://www.federaltimes.com/federal-oversight/congress/2018/01/31/withoutinvestment-us-risks-falling-behind-in-scientific-research/.

[40] American Association for the Advancement of Science, "Historical Trends in Federal R\&D," 2018. [Online]. Available: https://www.aaas.org/page/historical-trends-federalrd.

[41] B. Guarino, E. Rauhala and W. Wan, "The Washington Post," 3 June 2018. [Online]. Available: https://www.washingtonpost.com/national/health-science/china-challengesamerican-dominance-of-science/2018/06/03/c1e0cfe4-48d5-11e8-827e190efaf1f1ee_story.html?utm_term=.d849c5ae215c.

[42] S. Williams, "Science," 4 November 2016. [Online]. Available: http://www.sciencemag.org/features/2016/11/foreign-born-scientists-find-home-china.

[43] M. Jamrisko and W. Lu, "Bloomberg," 22 January 2018. [Online]. Available: https:/www.bloomberg.com/news/articles/2018-01-22/south-korea-tops-globalinnovation-ranking-again-as-u-s-falls.

[44] J. Horst and F. Santiago, "What can Policymakers Learn from Germany's Industrie 4.0 Development Strategy?," UNIDO (United Nations Industrial Development Organization), 2018.

[45] Popular Science, "China is opening a new quantum research supercenter," October 2017. [Online]. Available: https://www.popsci.com/chinas-launches-new-quantumresearch-supercenter.

[46] Synced, "Alibaba Pumps US\$15 Billion into Quantum Computing \& AI," October 2017. [Online]. Available: https://syncedreview.com/2017/10/11/alibaba-pumps-us15billion-into-quantum-computing-ai/.

[47] CSIS (Center for Strategic and International Studies), "Chinese Advances in Emerging Technologies and their Implications for U.S. National Security," 2018. 
[48] International Federation of Robotics, "World Robotics Report 2016," 29 September 2016. [Online]. Available: https://ifr.org/ifr-press-releases/news/world-robotics-report2016.

[49] N. G. Ruiz, "Brookings," 29 August 2014. [Online]. Available: https://www.brookings.edu/interactives/the-geography-of-foreign-students-in-u-shigher-education-origins-and-destinations/.

[50] R. Hearps, "Global Trends \& Disruptors in International Student Referrals," International Consultants for Education and Fairs (ICEF), 2016.

[51] E. Redden, "Inside Higher Ed," 2 May 2018. [Online]. Available: https://www.insidehighered.com/news/2018/05/02/white-house-reportedly-weighsrestrictions-chinese-citizens-doing-sensitive-research.

[52] Bureau International des Poids et Mesures, "Calibration and Measurement Capabilities - CMCs," 2018. [Online]. Available: https://kcdb.bipm.org/appendixC/default.asp.

[53] D. Desilver, "Congress has long struggled to pass spending bills on time," Pew Research Center, 2018.

[54] S. Stolberg and N. Fandos, "As Gridlock Deepens in Congress, Only Gloom Is Bipartisan," The New York Times, 17 January 2018.

[55] S. Larson, "The hacks that left us exposed in 2017," CNNtech, December 2017. [Online]. Available: https://money.cnn.com/2017/12/18/technology/biggestcyberattacks-of-the-year/index.html.

[56] National Renewable Energy Laboratory, "Renewable Electricity Futures Study," National Renewable Energy Laboratory, Golden, CO., 2012.

[57] U. Irfan, "Japan Bets on a Hydrogen-Fueled Future," Scientific American, May 2016. [Online]. Available: https://www.scientificamerican.com/article/japan-bets-on-ahydrogen-fueled-future/.

[58] B. d'Armagnac, "Danish wind farms show sustainable attitude to renewable energy," August 2010. [Online]. Available:

https://www.theguardian.com/world/2010/aug/10/denmark-renewable-wind-farmenergy.

[59] A. Bernaert, "www.weforum.org," 10 April 2015. [Online]. Available: https://www.weforum.org/agenda/2015/04/five-global-health-trends-you-just-cantignore/. 
[60] P. Perry, "big think," 18 July 2017. [Online]. Available: https://bigthink.com/philipperry/this-years-top-10-emerging-technologies-according-to-the-world-economicforum.

[61] Regulatory Focus, "www.raps.org," 11 March 2016. [Online]. Available: https://www.raps.org/regulatory-focus\%E2\%84\%A2/news-articles/2016/3/precisionmedicine-technology,-regulations-and-challenges.

[62] B. Mesko, "The role of artificial intelligence in precision medicine," Expert Review of Precision Medicine and Drug Development , vol. 2, no. 5, pp. 239-241, 2017.

[63] MarketWatch, "Internet of Things (IoT) Market Worth USD 2488 Billion by 2022 at 19.75\% CAGR," 22 August 2018. [Online]. Available:

https://www.marketwatch.com/press-release/internet-of-things-iot-market-worth-usd2488-billion-by-2022-at-1975-cagr-iot-industry-forecast-by-software-hardwareservices-organization-type-2018-08-22.

[64] P. Gao, H.-W. Kaas, D. Mohr and D. Wee, "Disruptive trends that will transform the auto industry," McKinsey\&Company, 2016. [Online]. Available: https://www.mckinsey.com/industries/automotive-and-assembly/ourinsights/disruptive-trends-that-will-transform-the-auto-industry.

[65] C. Gilbertsen, "www.thedrive.com," 27 March 2017. [Online]. Available: http://www.thedrive.com/tech/8657/heres-how-the-sensors-in-autonomous-cars-work.

[66] K. Campbell, J. Diffley, B. Flanagan, B. Morelli, O. Brendan and F. Sideco, "IHS Economics \& IHS Tecnology," January 2017. [Online]. Available: https://cdn.ihs.com/www/pdf/IHS-Technology-5G-Economic-Impact-Study.pdf.

[67] Pega, "Pega," 2018. [Online]. Available: https://www1.pega.com/system/files/resources/2017-11/what-consumers-really-thinkof-ai-infographic.pdf.

[68] PwC, "PwC Global," 2018. [Online]. Available: https://www.pwc.com/gx/en/issues/data-and-analytics/publications/artificialintelligence-study.html.

[69] K. Dow and M. Hancock, "INJECTING ETHICAL CONSIDERATIONS IN INNOVATION VIA STANDARDS - KEEPING HUMANS IN THE AI LOOP," InSight IEEE, 25 April 2018.

[70] P. Bajpai, "Quantum Computing: What It Is, And Who The Major Players Are," Nasdaq, pp. https://www.nasdaq.com/article/quantum-computing-what-it-is-and-whothe-major-players-are-cm939998, 26 March 2018. 
[71] K. W. Crane, L. G. Joneckis, H. Acheson-Field, I. D. Boyd, B. A. Corbin, X. Han and R. N. Rozansky, "Assessment of the Future Economic Impact of Quantum Information Science," IDA Science \& Technology Institute, Washington, D.C., 2017.

[72] Market Research Media, "Quantum Computing Market Forecast 2017-2022," 2018.

[73] Symantec Security Response, "Symantec," 27 October 2016. [Online]. Available: https://www.symantec.com/connect/blogs/mirai-what-you-need-know-about-botnetbehind-recent-major-ddos-attacks.

[74] S. Schroeder, "Verge cryptocurrency hack shows, no, blockchain isn't invincible," Mashable, 5 April 2018. [Online]. Available: https://mashable.com/2018/04/05/vergecrypto-hack/\#vqh6hVgq6iqR.

[75] W. Zhao, "Coinrail Exchange Hacked, Loses Possibly \$40 Million in Cryptos," Coindesk, 11 June 2018. [Online]. Available: https://www.coindesk.com/coinrailexchange-hacked-loses-possibly-40-million-in-cryptos.

[76] M. Badkar, "Financial Times," 10 January 2018. [Online]. Available: https://www.ft.com/content/93b22cb1-0346-38be-bebf-d2e676e19621.

[77] Randstad, "Randstad," 22 August 2017. [Online]. Available: https://www.randstadusa.com/about/news/employers-must-redefine-stem-to-attractfuture-talent-according-to-new-randstad-us-data/.

[78] BIPM, June 2018. [Online]. Available: https://kcdb.bipm.org/.

[79] Transparency Market Research, March 2016. [Online]. Available: https://www.transparencymarketresearch.com/pressrelease/companion-diagnosticsmarket.htm.

[80] J. Anderson and L. Rainie, "Pew Research Center," 19 October 2017. [Online]. Available: http://www.pewinternet.org/2017/10/19/the-future-of-truth-andmisinformation-online/.

[81] L. Gill, "TRUMP HAS SIGNED FEWEST BILLS INTO LAW OF ANY MODERN PRESIDENT, RESEARCH SHOWS," Newsweek, December 2017. [Online]. Available: http://www.newsweek.com/trump-has-signed-fewer-bills-law-any-modernpresident-research-shows-756111.

[82] AZoCleantech, "Study Finds Many Arctic Pollutants Decrease Following Stockholm Convention," August 2018. [Online]. Available: https://www.azocleantech.com/news.aspx?newsID=25738. 